\title{
Postsynaptic Clustering and Activation of Pyk2 by PSD-95
}

\author{
Jason A. Bartos, ${ }^{1}$ Jason D. Ulrich, ${ }^{1}$ Hongbin Li, ${ }^{3}$ Michael A. Beazely, ${ }^{3}$ Yucui Chen, ${ }^{1}$ John F. MacDonald, ${ }^{3,4}$ \\ and Johannes W. Hell ${ }^{1,2}$ \\ ${ }^{1}$ Department of Pharmacology, Roy J. and Lucille A. Carver College of Medicine, University of Iowa, Iowa City, Iowa 52242-1109, ${ }^{2}$ Department of \\ Pharmacology, University of California, Davis, Davis, California 95616-8636, ${ }^{3}$ Department of Physiology, University of Toronto, Toronto, Ontario M5S 1A8, \\ Canada, and ${ }^{4}$ Robarts Research Institute, University of Western Ontario, London, Ontario N6A 5K8, Canada
}

The tyrosine kinase Pyk2 plays a unique role in intracellular signal transduction by linking $\mathrm{Ca}^{2+}$ influx to tyrosine phosphorylation, but the molecular mechanism of Pyk2 activation is unknown. We report that Pyk2 oligomerization by antibodies in vitro or overexpression of PSD-95 in PC6-3 cells induces trans-autophosphorylation of Tyr402, the first step in Pyk2 activation. In neurons, $\mathrm{Ca}^{2+}$ influx through NMDA-type glutamate receptors causes postsynaptic clustering and autophosphorylation of endogenous Pyk2 via $\mathrm{Ca}^{2+}-a^{2}$ calmodulin-stimulated binding to PSD-95. Accordingly, $\mathrm{Ca}^{2+}$ influx promotes oligomerization and thereby autoactivation of Pyk2 by stimulating its interaction with PSD-95. We show that this mechanism of Pyk2 activation is critical for long-term potentiation in the hippocampus $\mathrm{CA1}$ region, which is thought to underlie learning and memory.

\section{Introduction}

Pyk2 consists of a FERM (band 4.1/ezrin/radixin/moesin homology), kinase, proline-rich, and focal adhesion targeting (FAT) domain (targets the homologous focal adhesion kinase FAK to focal adhesions) (see Fig. 1A) (Avraham et al., 1995; Lev et al., 1995; Sasaki et al., 1995; Yu et al., 1996). Tyr402 between the FERM and kinase domain becomes autophosphorylated during Pyk2 activation (Dikic et al., 1996; Salter and Kalia, 2004). Pyk2 is stimulated by depolarization-induced $\mathrm{Ca}^{2+}$ influx (Earp et al., 1995; Lev et al., 1995; Della Rocca et al., 1997; Girault et al., 1999) or PKC (Lev et al., 1995; Dikic et al., 1996; Girault et al., 1999; Huang et al., 2001; Salter and Kalia, 2004). However, it is unclear how $\mathrm{Ca}^{2+}$ or PKC activates Pyk2.

Phosphorylated Tyr402 stimulates Src by binding its Src homology 2 domain. Src in turn phosphorylates Tyr579 and Tyr580 in the activation loop of Pyk2 to enhance its catalytic activity (Lev et al., 1995; Dikic et al., 1996; Barsacchi et al., 1999; Avraham et al., 2000). Pyk2-activated Src also phosphorylates NR2 subunits to increase NMDA receptor (NMDAR) peak currents, which is important for induction of long-term potentiation (LTP) (Wang and Salter, 1994; Chen and Leonard, 1996; Köhr and Seeburg,

\footnotetext{
Received Sept. 6, 2008; revised Nov. 1, 2009; accepted Nov. 4, 2009.

This work was supported by National Institutes of Health (NIH) Grants R01 NS046450 and R01 NS035563 (J.W.H.), Canadian Institutes of Health Research (CIHR) Grant 44008 (J.F.M.), NIH Predoctoral Training Grant T32 GM008365 (J.A.B., J.D.U.), American Heart Association Predoctoral Fellowship $0515567 Z$ (J.A.B.), NIH National Research Service Award F31 MH081420 (J.D.U.), and a (IHR postdoctoral award (M.A.B.). Parental viral vectors were provided and FIV viruses produced by the University of lowa Center for Gene Therapy for Cystic Fibrosis, which is supported by NIH Grant P30 DK54759. We thank Drs. L. M. Graves and H. S. Earp (University of North Carolina at Chapel Hill, Chapel Hill, NC) for the N- and C-terminal Pyk2 antibodies, Dr.P. DeCamilli (Yale University, New Haven, (T) for the anti-synapsin antibody, Dr. M. A. Shea (University of lowa, lowa City, IA) for purified calmodulin, Dr. S. Strack for the PC6-3 cell line, and Drs. J. C. Houtman (University of lowa, lowa City, IA) and Lee M. Graves (University of North Carolina at Chape Hill, (hapel Hill, NC) for critically reading this manuscript.

Correspondence should be addressed to Johannes W. Hell, Department of Pharmacology, School of Medicine, University of California at Davis, GBSF 3503, 451 East Health Sciences Drive, Davis, CA 95616-8636. E-mail: jwhell@ucdavis.edu.

DOI:10.1523/JNEUROSCI.4992-08.2010

Copyright $\odot 2010$ the authors $\quad 0270-6474 / 10 / 300449-15 \$ 15.00 / 0$
}

1996; Lu et al., 1998; Xiong et al., 1999; Huang et al., 2001; Salter and Kalia, 2004).

The FERM domain of FAK binds to its kinase domain causing autoinhibition (Lietha et al., 2007). An additional interaction of the FERM domain with the region containing Tyr397, which is homologous to Tyr402 in Pyk2, fosters the autoinhibited FAK conformation. How these structural features relate to Pyk2 activation is unclear, but the FERM domain of Pyk2 does play a role in regulating catalytic activity and localization to focal adhesions (Dunty and Schaller, 2002). $\mathrm{Ca}^{2+} /$ calmodulin from cell extracts can directly or indirectly induce Pyk2 activation (Kohno et al., 2008). This activation was inhibited by mutations in the FERM domain, which might mediate $\mathrm{Ca}^{2+} /$ calmodulin binding (Kohno et al., 2008). However, the homologous site is primarily buried in the FAK structure (Lietha et al., 2007) and unlikely to bind calmodulin. The above findings do not explain how FAK and Pyk2 are generally activated or specifically by $\mathrm{Ca}^{2+}$ influx or PKC. In contrast to FAK Tyr397 autophosphorylation, which depends on Src, autophosphorylation of Tyr402 as the initial step in Pyk2 activation occurs often independent of Src (Park et al., 2004; Corvol et al., 2005; Wu et al., 2006) (but see Discussion and Sorokin et al., 2001; Cheng et al., 2002). Also, deletion of the FERM domains leads to autophosphorylation of FAK on Tyr397 but not of Pyk2 on Tyr 402 (Wu et al., 2006).

PSD-95 links Pyk2 to NMDARs (Seabold et al., 2003). PSD-95 binds with its $\mathrm{Src}$ homology 3 (SH3) domain to the proline-rich region of Pyk2 (see Fig. 1A) (Seabold et al., 2003) and via PDZ domains to NMDAR C termini (Kornau et al., 1995; Kim et al., 1996). We found that NMDAR-mediated $\mathrm{Ca}^{2+}$ influx induces postsynaptic clustering and trans-autophosphorylation of Pyk2 on Tyr402 by PSD-95 binding. This event is stimulated by $\mathrm{Ca}^{2+} /$ calmodulin and critical for LTP.

\section{Materials and Methods}

Ethical approval. All animal procedures had been approved by the University of Iowa and followed National Institutes of Health guidelines or 
were performed in agreement with the guidelines of the policies on the Use of Animals at the University of Toronto.

Antibodies and other reagents. Rabbit polyclonal antibodies against the $\mathrm{N}$ - and C-terminal portions of Pyk2 (residues 1-80 and 680-860, respectively) were provided by Drs. L. M. Graves and H. S. Earp (University of North Carolina at Chapel Hill, Chapel Hill, NC). These antibodies have been characterized and used extensively for immunofluorescence and immunoprecipitation (Yu et al., 1996; Li et al., 1999; Seabold et al., 2003). The mouse monoclonal anti-Pyk2 antibody, recognizing residues 833899, was purchased from BD Transduction Laboratories. Rabbit polyclonal phosphospecific antibody against Pyk2 pY402 was purchased from Biosource International. Rabbit polyclonal anti-PSD-95 antibody was produced against residues 494-510 and purified as described previously (Sans et al., 2000). The mouse monoclonal antibodies anti-PSD-95, anti-MAP2B, and anti-green fluorescent protein (GFP) were obtained from Affinity Bioreagents, BD Transduction Laboratories, and Covance Research Products, respectively. Rabbit polyclonal anti-glutathione $S$-transferase (GST) antibody was as described previously (Leonard et al., 1998). Rabbit polyclonal anti-synapsin antibody was provided by Dr. P. De Camilli (Yale University, New Haven, CT) (De Camilli et al., 1983). Chromatographically purified nonspecific rabbit and mouse IgG antibodies were purchased from Zymed. Horseradish peroxidase (HRP)conjugated goat anti-mouse and goat anti-rabbit secondary antibodies were purchased from Bio-Rad, and protein A HRP was purchased from GE Healthcare. Alexa Fluor-conjugated secondary antibodies, including goat anti-rabbit 568 , goat anti-mouse 488 , and goat anti-mouse 660 , were obtained from Invitrogen. Purified recombinant calmodulin was provided by Dr. M. A. Shea (University of Iowa, Iowa City, IA) (Akyol et al., 2004). MK801 [(+)-5-methyl-10,11-dihydro-5H-dibenzo [a,d] cyclohepten-5,10imine maleate], EGTA, HEPES, glutamate, NMDA, ionomycin, phorbol 12-myristate 13-acetate (PMA), trifluoperazine (TFP), and W7 [N-(6aminohexyl)-5-chloro-1-naphthalenesulfonamide] were purchased from Sigma, calmidazolium and calphostin C from Calbiochem, and bisindolylmaleimide and chelerythrine chloride from LC Laboratory. Pervanadate was prepared from $1 \mathrm{~m}$ sodium orthovanadate (Sigma) dissolved in $\mathrm{H}_{2} \mathrm{O}$, pH 10 (the solution was heated at $60^{\circ} \mathrm{C}$ until the solution became clear), by addition of $\mathrm{H}_{2} \mathrm{O}_{2}$ at a 1:1 ratio no more than 15 min before use.

Expression constructs. Bacterial expression vectors for GST fused to the $\mathrm{N}$ terminus of full-length PSD-95 and the SH3 domain of PSD-95 (residues 431-500) were provided by Dr. C. C. Garner (Stanford University, Palo Alto, CA) and Dr. B. Kay (University of Illinois at Chicago, Chicago, IL), respectively. GST was expressed using the pGEX4T-1 vector (Pfizer). His-tagged Pyk2(1-1009) was produced by ligating the Pyk2 cDNA encoding residues 1-1009 into the BamHI and EcoRI sites of pET28a. N-terminally GST-tagged Pyk2(671-875) was constructed using PCR amplification of the fragment and subsequent ligation into the BamHI and EcoRI sites of pGEX4T-1. PCR primers were the $5^{\prime}$ primer $5^{\prime}$-CAT CAT GGA TCC CGC TTT ACG GAG CTT GTG TGC AGT CTC- ${ }^{\prime}$ ' and 3' primer 5'-CAC GAG GAA TTC TCA CCT GTC CAA GTT GGC TGT AGG CTG GAT-3'. For expression in mammalian cell lines, PSD-95 pCMV vector was provided by Dr. C. C. Garner. GFP expression was achieved with pEGFP-C3 (Clontech). For production of enhanced GFP (EGFP) constructs, the pEGFP-C3 multiple cloning site was modified by annealing and ligating corresponding primers into the $\mathrm{XhoI}$ and $\mathrm{XbaI}$ sites of pEGFP-C3. The 5' primer was $5^{\prime}$-phos-TCG AGG GCG GCC GCG GAT CCG ATA TCA AGC TTG CTA GCG AAT TCG TCG ACT$3^{\prime}$, and the $3^{\prime}$ primer was $5^{\prime}$-phos-CTA GAG TCG ACG AAT TCG CTA GCA AGC TTG ATA TCG GAT CCG CGG CCG CCC-3'. The new vector (pEGFP-C3G) was used to transfer constructs directly from pGEX4T-1 vectors. Pyk2(1-1009)-GFP was constructed by BamHI/ EcoRI-mediated excision of the fragment and subsequent ligation into the pEGFP-C3G vector. PSD-95 SH3-GFP (residues 431-500) was constructed by cutting the SH3 domain from PSD-95 SH3-GST with EcoRI. It was then ligated into the $\mathrm{pEGFP}-\mathrm{C} 3 \mathrm{G}$ vector. All sequences were verified before use of the construct.

Lentiviral constructs. The University of Iowa Center for Gene Therapy for Cystic Fibrosis provided the feline immunodeficiency virus (FIV) parent vector ( $\mathrm{pVETL}$ ) and produced the final viral vectors (Johnston et al., 1999; Stein and Davidson, 2002). PSD-95 SH3-GFP pVETL (residues
431-500) was constructed using AgeI and SalI to excise PSD-95 SH3GFP from the pEGFP-C3G construct, followed by Klenow-mediated filling of the overhangs and blunt-end ligation into the EcoRV site of pVETL. The sequences were verified before submitting them to the University of Iowa Center for Gene Therapy for Cystic Fibrosis for production of the virus. The viral titers varied between $1 \times 10^{6}$ and $1 \times 10^{8}$.

Expression of fusion proteins. GST- and poly-His-tagged fusion constructs were transformed into Escherichia coli by electroporation. Cells were grown in Lauria broth and induced at an optical density of $0.6-0.8$ with $0.2 \mathrm{~mm}$ isopropyl $\beta$-D-thiogalactoside (IPTG). Cells were then collected by centrifugation and frozen for storage. For purification, cell pellets were thawed, resuspended, and incubated for $30 \mathrm{~min}$ in ice-cold TBS (150 $\mathrm{mm} \mathrm{NaCl}$ and $15 \mathrm{~mm}$ Tris-Cl, pH 7.4) containing $100 \mu \mathrm{g} / \mathrm{ml}$ lysozyme and a low concentration of protease inhibitors [200 $\mu \mathrm{M}$ phenylmethylsulphonylfluoride (PMSF), $1 \mu \mathrm{g} / \mathrm{ml}$ pepstatin A, $2 \mu \mathrm{g} / \mathrm{ml}$ aprotinin, and $1 \mu \mathrm{g} / \mathrm{ml}$ leupeptin]. Sarkosyl (1.5\%) and $\beta$-mercaptoethanol (10 mM) were then added for $15 \mathrm{~min}$ on ice. Once the incubation was complete, lysates were centrifuged for $45 \mathrm{~min}$ at $250,000 \times \mathrm{g}$. The supernatants were removed and neutralized with $2 \%$ Triton X-100.

Transient transfection of PC6-3 cells. PC6-3 cells (supplied by Dr. S. Strack, University of Iowa, Iowa City, IA) were seeded at $2.5 \times 10^{6}$ cells per $100 \mathrm{~mm}$ dish in RPMI medium (RPMI 1640 supplemented with 5\% horse serum, $5 \%$ fetal bovine serum, $5 \%$ calf serum, $0.5 \%$ penicillin/ streptomycin, $1 \%$ glutamine, and $1 \mathrm{~mm}$ sodium pyruvate). Cells were transfected with Lipofectamine 2000 when $80-90 \%$ confluent. Briefly, 30 $\mu \mathrm{g}$ of DNA was added to serum-free Opti-MEM. An $8 \%$ Lipofectamine 2000 solution was made simultaneously in serum-free Opti-MEM. After $5 \mathrm{~min}$ at room temperature, the DNA mix was added to the Lipofectamine mix, followed by a $20 \mathrm{~min}$ incubation at room temperature. The medium on the cells was then replaced with Opti-MEM, followed by addition of the DNA/Lipofectamine solution. The dishes were gently mixed and incubated for $6 \mathrm{~h}$. The medium was then replaced with RPMIcontaining serum. The cells were harvested $48 \mathrm{~h}$ after transfection using a cell scraper and Triton X-100 homogenization buffer (1\% Triton X-100, $150 \mathrm{~mm} \mathrm{NaCl}, 10 \mathrm{~mm}$ Tris-Cl, 20 mm EDTA, and 10 mм EGTA, pH 7.4) containing protease inhibitors (here $200 \mu \mathrm{M}$ PMSF, $1 \mu \mathrm{g} / \mathrm{ml}$ pepstatin A, $20 \mu \mathrm{g} / \mathrm{ml}$ aprotinin, $10 \mu \mathrm{g} / \mathrm{ml}$ leupeptin, and $8 \mu \mathrm{g} / \mathrm{ml}$ calpain inhibitor I/II) and phosphatase inhibitors ( $1 \mathrm{~mm}$ pervanadate, $25 \mu \mathrm{M} \mathrm{NaF}$, and 25 $\mathrm{mm} \mathrm{NaPPi}$ ). The cells were then homogenized with a dounce homogenizer, followed by centrifugation at $250,000 \times g$ for $15 \mathrm{~min}$. Supernatant was removed, and the total protein was quantified with a BCA assay. An equal amount of protein $(25 \mu \mathrm{g})$ was extracted with SDS sample buffer and loaded for SDS-PAGE and subsequent immunoblotting with phosphospecific pY402 Pyk2 antibody. The immunoblots were then stripped and reprobed for total Pyk2 using the monoclonal anti-Pyk2 antibody.

Primary hippocampal culture production and maintenance. Primary hippocampal cultures were prepared as described previously (Lim et al., 2003; Chen et al., 2008). Briefly, hippocampi from embryonic day 18 Harlan Sprague Dawley rats were removed and incubated in HBSS (Invitrogen) with trypsin $(0.03 \%)$ for $15 \mathrm{~min}$ at $37^{\circ} \mathrm{C}$. The cells were then washed three times with HBSS, followed by trituration to dissociate cells. Dissociated cells were counted and plated for immunofluorescence on glass coverslips $(60,000$ cells per $35 \mathrm{~mm}$ dish) for microscopic analysis or in $100 \mathrm{~mm}$ culture dishes (800,000 cells per $100 \mathrm{~mm}$ dish) for biochemical analysis. The cells were incubated in Neurobasal medium (Invitrogen) containing custom-made NS21 supplement (Chen et al., 2008), 0.6 mu glutamine, and 5\% fetal bovine serum (Brewer et al., 1993). After 3-4 $\mathrm{h}$, the incubation medium was replaced with serum-free medium, and cells were maintained at $37^{\circ} \mathrm{C}$ in humidified air composed of $95 \%$ air and $5 \% \mathrm{CO}_{2}$. One-third of the medium was exchanged weekly.

Transient transfection of primary hippocampal cultures. Primary hippocampal cultures [15 $\mathrm{d}$ in vitro (DIV)] were transfected using an adapted calcium phosphate protocol. The medium was replaced with freshly prepared Neurobasal medium containing NS21 30 min before transfection. The removed conditioned medium was then retained for use later in the procedure. DNA $(5 \mu \mathrm{g})$ was added to $\mathrm{CaCl}_{2}(200 \mathrm{~mm})$. An equal volume of $2 \times \mathrm{BBS}$ (final concentrations in mM: $140 \mathrm{NaCl}, 0.75$ $\mathrm{Na}_{2} \mathrm{HPO}_{4}$, and $25 \mathrm{~N}, \mathrm{~N}$-bishydroxyethyl-2-aminoethane-sufonic acid, $\mathrm{pH}$ 7.1) was added dropwise, followed by immediate vortexing. The 
DNA/BBS mixture was then added dropwise to the neurons, followed by gentle mixing. After a $3.5 \mathrm{~h}$ incubation, the medium was removed and the cultures were washed once with HBSS (in mM: $135 \mathrm{NaCl}, 4 \mathrm{KCl}, 1$ $\mathrm{Na}_{2} \mathrm{HPO}_{4}, 2 \mathrm{CaCl}_{2}, 1 \mathrm{MgCl}_{2}, 10$ glucose, and 20 HEPES, $\mathrm{pH}$ 7.35). Immediately after the wash, the conditioned medium was added. The cultures were allowed to express protein for $72 \mathrm{~h}$ at $37^{\circ} \mathrm{C}$ in humidified air composed of $95 \%$ air and $5 \% \mathrm{CO}_{2}$, followed by use for immunofluorescence.

Infection of primary hippocampal cultures. Primary hippocampal cultures (15 DIV) were infected using FIV carrying GFP-tagged PSD-95 $\mathrm{SH}$. Cultures (100 $\mathrm{mm}$ dishes) received virus at a multiplicity of infection of 10:1. The virus was added, followed by gentle mixing. After $24 \mathrm{~h}$, half of the medium was replaced with fresh Neurobasal medium supplemented with NS21. Immunofluorescence and biochemical studies were initiated $72 \mathrm{~h}$ after infection.

Stimulation of hippocampal cultures for biochemical analysis and use of various agonists and antagonists. Cultures (18 DIV, $100 \mathrm{~mm}$ plates) were pretreated with calmodulin inhibitors (W7, TFP, and calmidazolium) for $30 \mathrm{~min}$, with tetrodotoxin (TTX) for $15 \mathrm{~min}$, and with pervanadate for $5 \mathrm{~min}$ if indicated before stimulation with vehicle, NMDA, ionomycin, or PMA for $15 \mathrm{~min}$. The three different calmodulin inhibitors block $\mathrm{Ca}^{2+}$-dependent binding of calmodulin to substrates and were used to evaluate the role of calmodulin in the interaction between Pyk2 and PSD-95, as well as Pyk2 activation, at the following concentrations: W7 at $10 \mu \mathrm{M}, \mathrm{TFP}$ at $20 \mu \mathrm{M}$, and calmidazolium at $30 \mu \mathrm{M}$ (Schweitzer, 1987; Wakamori et al., 1993; Della Rocca et al., 1997; Liu et al., 1999; Heidinger et al., 2002). W7 is a member of the naphthalene-sulfonamide class of drugs, which also appears to block NADPH oxidase activation by arachidonate (Sakata et al., 1987). TFP, a member of the phenothiazine family, is the best characterized calmodulin antagonist because crystal structures have been solved illustrating its interaction with calmodulin (Cook et al., 1994; Vandonselaar et al., 1994). However, similar to W7, TFP can inhibit NADPH oxidase activation. Calmidazolium can inhibit adenylyl cyclase activity at concentrations ranging between 20 and $50 \mu \mathrm{M}$ (Haunsø et al., 2003). However, using each of the three inhibitors individually ensures that the observed inhibition of Pyk2 binding to PSD-95 and the ensuing Pyk2 activation is attributable to their common inhibition of calmodulin instead of idiosyncratic side effects. Bath application of the specific NMDAR agonist NMDA in the presence of TTX is an established method for analyzing signaling pathways involving the NMDAR (Hell et al., 1996; Siciliano et al., 1996; Leonard et al., 1999; Ahmed et al., 2006). Of specific relevance to our studies, Src signaling downstream of NMDAR activation and the ensuing NMDAR potentiation have been monitored in intact neurons with NMDA treatments lasting $15 \mathrm{~min}$ (Lu et al., 1999; Crossthwaite et al., 2004). Similarly, the $\mathrm{Ca}^{2+}$ ionophore ionomycin is commonly used in studies on activation of Pyk2 by $\mathrm{Ca}^{2+}$ influx at $1 \mu \mathrm{M}$ for 10-30 min (Sabri et al., 1998; Byron and Lucchesi, 2002; Cheng et al., 2002). PMA is a PKC activator that is often used to activate Pyk2 or test the role of PKC in Pyk2 signaling at $100 \mathrm{~nm}$ over 10-15 min and longer (Siciliano et al., 1996; Sabri et al., 1998; Lu et al., 1999, 2000; Huang et al., 2001; Frank et al., 2002).

Neurons were harvested immediately after treatments in $1 \mathrm{ml}$ of icecold deoxycholate homogenization buffer ( $1 \%$ deoxycholate, $137 \mathrm{~mm}$ $\mathrm{NaCl}, 50 \mathrm{~mm}$ Tris-Cl, $10 \mathrm{~mm}$ EDTA, and $10 \mathrm{~mm}$ EGTA, pH 8.5) containing protease and phosphatase inhibitors as before, followed by homogenization with a dounce homogenizer and high-speed centrifugation $(250,000 \times g$ for $15 \mathrm{~min})$. Supernatant was then collected for either immunoprecipitation or direct immunoblotting.

Preparation and treatment of acute cortical slices. Transverse cortical slices $(350 \mu \mathrm{m})$ were prepared from 21-d-old male Harlan Sprague Dawley rats (Hell et al., 1995; Leonard et al., 1999; Lim et al., 2003; Lu et al., 2007). Slices were sectioned in artificial CSF (ACSF) ( $127 \mathrm{~mm} \mathrm{NaCl}, 26$ mм $\mathrm{NaHCO}_{3}, 1.9 \mathrm{~mm} \mathrm{KCl}, 1.2 \mathrm{~mm} \mathrm{KH}_{2} \mathrm{PO}_{4}, 1 \mathrm{~mm} \mathrm{CaCl}_{2}, 2 \mathrm{~mm} \mathrm{MgSO}_{4}$, and $10 \mathrm{~mm}$ dextrose, $290-300 \mathrm{mOsm} / \mathrm{kg}$, equilibrated in $95 \% \mathrm{O}_{2} /$ $5 \% \mathrm{CO}_{2}$ ). Each slice was then incubated in ACSF for $30 \mathrm{~min}$ at $34^{\circ} \mathrm{C}$, followed by $30 \mathrm{~min}$ at $22^{\circ} \mathrm{C}$ with continuous aeration in a submersion chamber. Slices were then transferred to modified ACSF containing 2.2 $\mathrm{mm} \mathrm{CaCl}_{2}$ and $1 \mathrm{~mm} \mathrm{MgSO}_{4}$ for 15 min before pretreatment with calmodulin inhibitors (W7, TFP, and calmidazolium; $30 \mathrm{~min}$ ) and TTX (15 $\mathrm{min}$ ) if indicated and subsequent incubation with vehicle, NMDA, ionomycin, or PMA for $15 \mathrm{~min}$. Slices were immediately homogenized with a dounce homogenizer in $1 \mathrm{ml}$ of deoxycholate homogenization buffer ( $1 \%$ deoxycholate, $137 \mathrm{~mm} \mathrm{NaCl}, 50 \mathrm{~mm}$ Tris-Cl, $10 \mathrm{~mm}$ EDTA, and 10 mм EGTA, pH 8.5) containing protease and phosphatase inhibitors as before. Lysates were then centrifuged $(250,000 \times g$ for $15 \mathrm{~min})$, and supernatants were collected for immunoprecipitation or direct immunoblotting.

Preparation of cytosolic brain extracts. Male Harlan Sprague Dawley rats (8 weeks old) were anesthetized with halothane and decapitated. Brains were immediately placed in ice-cold sucrose buffer (in mM: 300 sucrose, 10 EDTA, 10 EGTA, 10 Tris-Cl, and 1 pervanadate, pH7.4) containing protease inhibitors as before, homogenized in a dounce homogenizer, and centrifuged at low speed $(5,000 \times g)$ to clear larger cell fragments and then at high speed $(200,000 \times g)$ to remove the crude membrane fraction. Supernatant was collected for use in experiments requiring the brain cytosol. Triton X-100 (1\%) was added to the isolated cytosol before use to reduce nonspecific interactions.

Immunoprecipitation. Triton X-100 extracts from hippocampal culture (one $100 \mathrm{~mm}$ dish), cortical slices (one slice), or brain (cytosol; $3 \mathrm{mg}$ of total protein unless otherwise noted) were added to protein A Sepharose (rabbit antibodies) or protein L Sepharose (mouse antibodies) along with $1 \mu \mathrm{g}$ of the desired antibody. Samples were incubated for $3 \mathrm{~h}$ at $4^{\circ} \mathrm{C}$, followed by washes with $0.1 \%$ Triton X-100/TBS. Experiments involving hippocampal culture or cortical slice lysates, when material was limited, used sequential immunoprecipitation with proper nonspecific and then specific antibody. Resins were washed with $0.1 \%$ Triton X-100/TBS before SDS-PAGE and immunoblotting.

Pyk2 autophosphorylation. Autophosphorylation in cytosolic extract, or after immunoprecipitation using $3 \mathrm{mg}$ of total protein as starting material (unless otherwise noted), was initiated with the addition of 2.5 mM ATP and $25 \mathrm{~mm} \mathrm{MgCl}_{2}$ or TBS as indicated. Incubation buffers also contained $50 \mu \mathrm{M}$ EGTA to remove free $\mathrm{Ca}^{2+}$ contaminations for nominally $\mathrm{Ca}^{2+}$-free conditions. For incubations in the presence of free $\mathrm{Ca}^{2+}$, $10 \mathrm{mM} \mathrm{CaCl}_{2}$ was added to this buffer. After $1 \mathrm{~h}$ at $4^{\circ} \mathrm{C}$, the reaction was terminated by addition of $50 \mathrm{~mm}$ EDTA or SDS sample buffer.

Pulldown assays. For pulldown of calmodulin by the bacterially expressed His-tagged SH3-GK module of PSD-95, this polypeptide was immobilized on $\mathrm{Ni}^{2+}$ chelate agarose (GE Healthcare), washed with $0.1 \%$ Triton X-100/TBS, and incubated with calmodulin in $0.1 \%$ Triton $\mathrm{X}-100 / \mathrm{TBS}$ containing $50 \mu \mathrm{m}$ EGTA. If indicated, $10 \mathrm{~mm} \mathrm{CaCl}_{2}$ was added to the incubation buffer. Resins were washed again with the same buffer used for incubation except calmodulin was omitted. For pulldown of PSD-95-GST by bacterially expressed Pyk2, Pyk2 was immunoprecipitated with the $\alpha \mathrm{N}$ Pyk2 antibody before incubation with GST or PSD-95-GST and washing analogous to the pulldown experiments with His-tagged SH3-GK.

Immunoblotting. Samples were extracted with SDS sample buffer (3\% SDS, $10 \%$ sucrose, $90 \mathrm{~mm}$ Tris-Cl, $20 \mathrm{~mm}$ DTT, and $60 \mu \mathrm{m}$ bromophenol blue) at $90^{\circ} \mathrm{C}$ for $10 \mathrm{~min}$, resolved by SDS-PAGE, and transferred to polyvinylidene fluoride membranes. Membranes were blocked with $7 \%$ milk/TBS for $2 \mathrm{~h}$, incubated with primary antibody for $2 \mathrm{~h}$ at room temperature or overnight at $4^{\circ} \mathrm{C}$, washed, incubated with HRPconjugated secondary antibodies for $1 \mathrm{~h}$ at room temperature, washed extensively, and developed with ECL detection kit (GE Healthcare). When indicated, membranes were stripped (2\% SDS, $20 \mathrm{~mm}$ DTT, and $62.5 \mathrm{~mm}$ Tris-Cl, pH 6.7), washed with water, and reprobed (Hell et al., 1993). Immunosignals were in the linear range and digitalized and quantified with Photoshop (Adobe Systems) as detailed previously (Davare and Hell, 2003; Merrill et al., 2007).

Immunofluorescence microscopy. Primary hippocampal neurons (18 DIV) were cultured on coverslips in $35 \mathrm{~mm}$ dishes, preincubated with W7 (10 $\mu \mathrm{M})$, EGTA (2 mM), or MK801 [10 $\mu \mathrm{M}$ (Lu et al., 1998; Fong et al., 2002; Gardoni et al., 2002)] for $30 \mathrm{~min}$ and with TTX for $15 \mathrm{~min}$, and treated with vehicle, glutamate, NMDA, ionomycin, or PMA for indicated time periods at $37^{\circ} \mathrm{C}$. Coverslips were rapidly washed with $\mathrm{PBS}$ (in mм: $137 \mathrm{NaCl}, 3 \mathrm{KCl}, 10 \mathrm{Na}_{2} \mathrm{HPO}_{4}$, and $1 \mathrm{KH}_{2} \mathrm{PO}_{4}, \mathrm{pH} 7.4$ ), fixed in $4 \%$ paraformaldehyde/ $4 \%$ sucrose/PBS for $15 \mathrm{~min}$, washed (three times for 5 min in PBS), permeabilized with $0.5 \%$ Triton X-100/PBS for $20 \mathrm{~min}$, 
washed (two times for $5 \mathrm{~min}$ in PBS), and incubated with blocking buffer (2\% glycerol, $5 \%$ FBS, $2 \%$ goat serum, and $50 \mathrm{~mm} \mathrm{NH}_{4} \mathrm{Cl}$ in PBS) for $2 \mathrm{~h}$ at room temperature and then with primary antibody in blocking buffer overnight at $4^{\circ} \mathrm{C}$. Antibodies included the $\mathrm{N}$-terminal anti-Pyk2 antibody (1:500), anti-PSD-95 (1:500), anti-bassoon (1:1,000), anti-MAP2B $(1: 1,000)$, and anti-synapsin $(1: 1,000)$. Coverslips were washed (three times for $5 \mathrm{~min}$ in PBS) and incubated with blocking buffer for $30 \mathrm{~min}$ and with secondary antibody (1:500) in blocking buffer for $1 \mathrm{~h}$ at $4^{\circ} \mathrm{C}$. Coverslips were washed with PBS (four times for $5 \mathrm{~min}$ ) and water (three times for $5 \mathrm{~min}$ ), mounted on slides using Prolong Antifade Gold Reagent (Invitrogen), and incubated for $24 \mathrm{~h}$ at $4^{\circ} \mathrm{C}$. Images were collected using an epifluorescence Olympus microscope with a $100 \times$ objective. Bandpass filter sets were $490 \mathrm{~nm} / 528 \mathrm{~nm}, 555 \mathrm{~nm} / 617 \mathrm{~nm}$, and 635 $\mathrm{nm} / 685 \mathrm{~nm}$. Negative controls included omission of primary antibody to exclude nonspecific signals from secondary antibodies and bleed through from other channels. Coverslips were coded and randomized for image collection by an individual, who was blind to the treatments. Identical exposure time and contrast settings were used for each field in a given experiment. The dendritic length and total number of puncta in each image were also determined in a blind manner. Dendritic length was calculated using NIH ImageJ, whereas puncta were quantified using a customized MATLAB package (MathWorks). The MATLAB package removed smoothly distributed staining like that found in dendritic shafts and the soma with the top-hat transform. A threshold value was determined and held constant for all images such that pixels with intensities below that level were disregarded. It then counted the remaining puncta, defined as a series of 5 or more contiguous pixels above threshold. Colocalization of Pyk2 and PSD-95 puncta was determined by designating the 10 pixels in each punctum with the highest intensity as the region of interest (ROI). Overlap of four pixels in two ROIs was required for colocalization. This provided two variables for comparison between various treatment groups. The first is the total number of puncta under different stimulation conditions, and the second is the colocalization of Pyk2 puncta with a synaptic marker such as PSD-95.

Cell isolation and whole-cell recording. CA1 neurons were isolated from hippocampal slices of postnatal day 14-21 Wistar rats as described previously (Wang and MacDonald, 1995). Whole-cell patch recordings were performed under perfusion at room temperature. The extracellular solution was composed of $140 \mathrm{~mm} \mathrm{NaCl}, 1.3 \mathrm{~mm} \mathrm{CaCl}_{2}, 25 \mathrm{~mm}$ HEPES, 33 mM glucose, $5.4 \mathrm{~mm} \mathrm{KCl}, 0.5 \mu \mathrm{M}$ tetrodotoxin, and $0.5 \mu \mathrm{M}$ glycine, $\mathrm{pH}$ 7.3-7.4, with osmolarity ranging from 320 to $330 \mathrm{mOsm}$. $\mathrm{No} \mathrm{Mg}^{2+}$ was added to record NMDA-evoked currents. The intracellular solution consisted of the following (in mM): 11 EGTA, 10 HEPES, $2 \mathrm{MgCl}_{2}$, 2 tetraethylammonium chloride, $1 \mathrm{CaCl}_{2}, 140 \mathrm{CsF}$, and $4 \mathrm{~K}_{2} \mathrm{ATP}$. NMDA currents were evoked by rapid application of NMDA $(50 \mu \mathrm{M})$ delivered from a multi-barreled fast perfusion system. NMDA was applied once every $60 \mathrm{~s}$ for a period of $3 \mathrm{~s}$. Glycine at $1 \mu \mathrm{M}$ was present throughout the recordings in the bath. The membrane potential was held at $-60 \mathrm{mV}$. A voltage step of $10 \mathrm{mV}$ was applied before NMDA application to monitor series resistance.

Whole-cell patch recordings from hippocampal slices. Transverse hippocampal slices were prepared from 4- to 6-week-old male Sprague Dawley rats and placed in a holding chamber for at least $1 \mathrm{~h}$ before recording. A single slice was transferred to the recording chamber and superfused with ACSF ( $2 \mathrm{ml} / \mathrm{min}$ ) composed of the following (in $\mathrm{mM}$ ): $124 \mathrm{NaCl}, 3$ $\mathrm{KCl}, 1.25 \mathrm{NaH}_{2} \mathrm{PO} 4,1.3 \mathrm{MgCl}_{2}, 2.6 \mathrm{CaCl}_{2}, 26 \mathrm{NaHCO}_{3}, 10$ glucose, and 0.01 bicuculline methiodide (saturated with $95 \% \mathrm{O}_{2}-5 \% \mathrm{CO}_{2}$ at $28-$ $30^{\circ} \mathrm{C}$ ). Synaptic responses were evoked with a bipolar tungsten electrode located $\sim 50 \mu \mathrm{m}$ from the cell body layer in CA1. Test stimuli were evoked at $0.05 \mathrm{~Hz}$ with the stimulus intensity set to $25 \%$ of maximal synaptic response. Tetanic stimulations consisted of two trains of $100 \mathrm{~Hz}$ stimuli lasting $500 \mathrm{~ms}$ at an intertrain interval of $10 \mathrm{~s}$ and were performed under current clamp. The average of EPSC amplitudes from the $5 \mathrm{~min}$ period immediately before tetanus was defined as baseline. For voltageclamp recordings, the patch pipette $(4-6 \mathrm{M} \Omega)$ solution contained the following (in mM):132.5 K-gluconate, $17.5 \mathrm{KCl}, 10 \mathrm{HEPES}, 0.2 \mathrm{EGTA}, 2$ Mg-ATP, 0.3 GTP, and 5 QX-314 [2(triethylamino)-N-(2,6-dimethylphenyl) acetamine], pH 7.25 (290 mOsm). The intracellular solution was supplemented with GST, GST-SH3, or GST-Pyk2(671-875) polypeptides.
The peptides were numbered, and the individual performing the recordings was unaware of which was applied in experiments. Patch recordings in slice were performed using the "blind" patch method. Cells were voltage clamped at $-65 \mathrm{mV}$. Data were used only after the access resistance had stabilized. Signals were amplified using an Axopatch 1-D, sampled at $5 \mathrm{kHz}$, and analyzed with pClamp6 software (Molecular Devices). Series resistance ranged from 10 to $20 \mathrm{M} \Omega$, as estimated from series resistance compensation of current responses to voltage steps of 5 $\mathrm{mV}$, and cells were discarded if the resistance changed by $>15 \%$.

To test whether the GST polypeptides affected basal synaptic NMDAR activity, NMDAR-mediated EPSCs were recorded in the presence of CNQX $(10 \mu \mathrm{M})$ to block AMPA-type glutamate receptors (AMPARs). To increase the amplitude of these currents, the holding potential of the neurons was transiently raised from -65 to $-40 \mathrm{mV}$ for $2.5 \mathrm{~s}$ whenever a test stimulus was applied.

Statistical analysis. Statistical analysis was performed in Prism (GraphPad Software). Statistical significance was determined using a paired two-tailed $t$ test with a $95 \%$ confidence interval. Three independent experiments were performed separately on different days for all quantifications. For each immunofluorescence experiment, 5-10 images were taken from any single coverslip, and values were averaged before statistical analysis for the means from the three independent experiments.

\section{Results}

\section{Pyk2 dimerization induces its autophosphorylation}

As the unique central intermediary between $\mathrm{Ca}^{2+}$ influx and tyrosine phosphorylation, Pyk 2 has been the subject of numerous studies. We attempted to stimulate Pyk 2 after immunoprecipitation from brain lysate by addition of $\mathrm{Ca}^{2+}$ and calmodulin. Surprisingly, addition of Mg-ATP alone to Pyk2 immunocomplexes was sufficient to induce strong Tyr402 phosphorylation (Fig. $1 B$, compare lanes 2, 4), an established and reliable readout for Pyk2 activation (Dikic et al., 1996; Park et al., 2004). Neither $\mathrm{Ca}^{2+}$ alone nor $\mathrm{Ca}^{2+}$ /calmodulin enhanced this autophosphorylation. In agreement with previous findings (Lev et al., 1995), these data indicate that $\mathrm{Ca}^{2+}$ and calmodulin alone are not sufficient to stimulate autoactivation of Pyk2. Furthermore, autophosphorylation was unaffected by inclusion of a mixture of three structurally and functionally different PKC inhibitors (Fig. $1 B$, compare lanes 10,11$)$. We also evaluated whether $\mathrm{Ca}^{2+} /$ calmodulin or calcium/calmodulin-dependent kinase II (CaMKII) were present in Pyk2 immunoprecipitates from rat brain with negative results (data not shown), yet Pyk2 effectively autophosphorylated in such immunocomplexes (Fig. 1B). Accordingly, antibodyinduced autophosphorylation bypasses the $\mathrm{Ca}^{2+}$ and PKC dependence of Pyk2 activation.

The effective autophosphorylation of Pyk2 in the immunocomplexes, which was not observed if Pyk2 is in solution (Fig. 1C, lanes 1,8 ), suggests that dimerization of Pyk2 itself can induce the phosphorylation reaction. Such a mechanism would be analogous to trans-autophosphorylate by several receptor-type tyrosine kinases during ligand-induced dimerization (Ullrich and Schlessinger, 1990; Hubbard and Miller, 2007), which induces structural changes in their activation loops to disinhibit their catalytic domains (Zhang et al., 2006). In fact, overexpression of Pyk2 leads to its activation via trans-autophosphorylation of Tyr402 (Park et al., 2004). Although stable Pyk2 oligomers were not observed in this study, an attractive explanation is that high enough concentrations of Pyk2 foster transient or semi-stable formation of protein complexes that aligns two Pyk2 polypeptides for trans-autophosphorylation.

To determine whether dimerization is sufficient to induce autophosphorylation of Pyk2 in brain cytosol, three different Pyk2 antibodies targeting various regions of Pyk2 were used: a polyclonal antibody directed against the $\mathrm{N}$-terminal 80 residues 
A

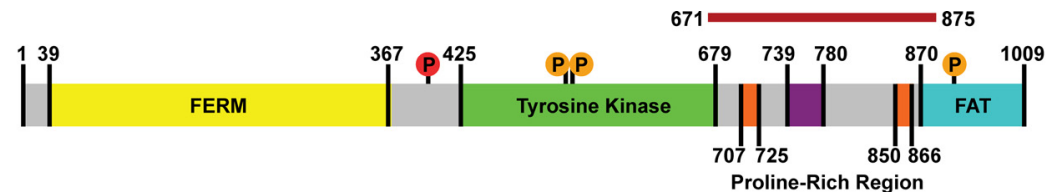

B

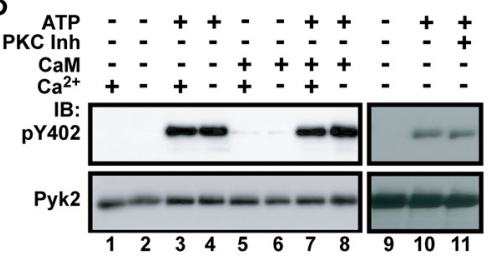

C

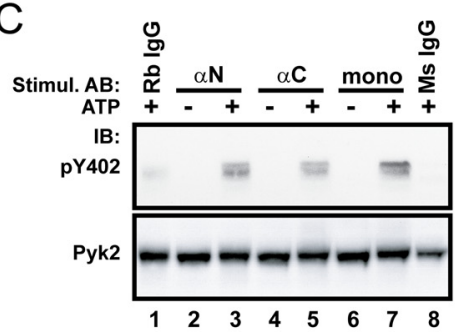

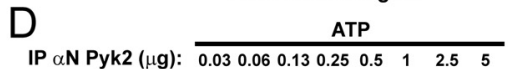

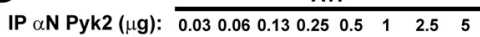

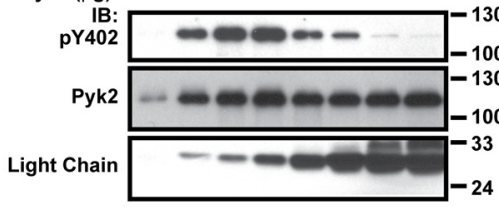

E

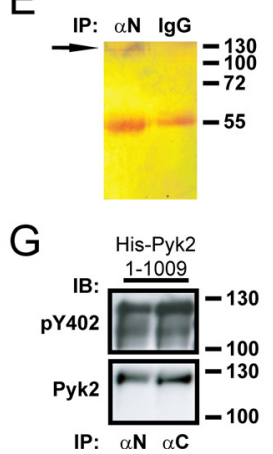

F

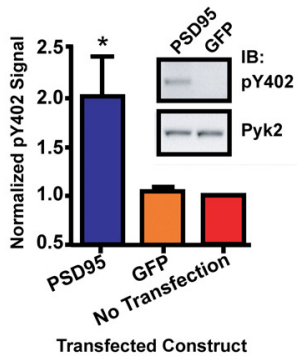

Figure 1. Pyk2 dimerization by antibodies or by PSD-95 induces autophosphorylation. $\boldsymbol{A}$, Schematic of Pyk2 depicting the FERM, tyrosine kinase, and FAT domains. Proline-rich segments are orange. Src phosphorylation sites are denoted as orange circles, and the autophosphorylation site (Tyr402) is red. The magenta bar on top represents the PSD-95 binding region (residues 671875). B, Pyk2 was immunoprecipitated ( $\alpha \mathrm{N}$ Pyk2 antibody) from rat brain cytosol and incubated for $1 \mathrm{~h}$ at $4^{\circ} \mathrm{C}$ in the absence or presence of Mg-ATP, $\mathrm{Ca}^{2+}(10 \mathrm{~mm})$, calmodulin $(10 \mu \mathrm{m})$, or a mixture of PKC inhibitors (200 nm bisindolylmaleimide, $5 \mu \mathrm{m}$ chelerythrine chloride, and $1 \mu \mathrm{m}$ calphostin C) before immunoblotting with anti-phospho-Tyr402 (pY402), followed by reprobing with the monoclonal Pyk2 antibody. Autophosphorylation occurred independent of $\mathrm{Ca}^{2+} /$ calmodulin (compare lanes 3, 4,7,8) or PKC activity (lanes 10,11). C, Rat brain cytosol was incubated with $\alpha \mathrm{N}, \alpha \mathrm{C}$, monoclonal Pyk2 antibodies, or nonspecific rabbit or mouse lgG in the absence or presence of Mg-ATP as indicated and directly analyzed by immunoblotting with anti-phospho-Tyr402 and subsequently the monoclonal Pyk2 antibody. $\boldsymbol{D}$, Increasing amounts of $\alpha \mathrm{N}$ Pyk2 antibody were immobilized on protein $\mathrm{A}$ Sepharose, washed, incubated with identical amounts of rat brain cytosol, washed, incubated with $\mathrm{Mg}^{2+}-\mathrm{ATP}$ for $1 \mathrm{~h}$ at $4^{\circ} \mathrm{C}$, and processed for immunoblotting with anti-phospho-Tyr402 and subsequently monoclonal Pyk2 antibody and an antibody against the light chain of the immunoprecipitating antibody. $\boldsymbol{E}$, Immunoprecipitation from brain lysate with antibodies against Pyk2 ( $\alpha \mathrm{N})$ or control rabbit IgG was followed by SDS-PAGE and silver staining. The thin band near the top of the blot corresponding to the molecular size of Pyk2 is labeled with an arrow and absent in control precipitates. The bands at $55 \mathrm{kDa}$ are the heavy chains of the antibodies used in the immunoprecipitations. F, PC6-3 cells were transfected with PSD-95 $24 \mathrm{~h}$ before immunoblotting. Immunosignals were quantified by film densitometry and phospho-Tyr402 values (top of inset) per total Pyk2 signal (bottom of inset) normalized to the no-transfection control. Shown are averages \pm SEM of $n=3$. ${ }^{*} p<0.05$, statistically different from GFPtransfected cells by $t$ test. $G$, E. coli was transformed with pET28a carrying His-tagged Pyk2 and expression induced with IPTG before extraction and immunoblotting with anti-phospho-Tyr402, followed by probing for total Pyk2. The lower band in the phosphoprobing is likely a slightly truncated degradation product and was not visible in the reprobing for total Pyk2 because the reprobing was less sensitive than the original phospho-probing. $\mathbf{A}-\mathbf{G}$, All blots are representative of three independent experiments. IB, Immunoblots; IP, immunoprecipitation.

of Pyk2 $(\alpha \mathrm{N})$, a polyclonal antibody recognizing residues 680860 of Pyk2 $(\alpha \mathrm{C})$, and a monoclonal antibody targeting residues 833-899 of Pyk2 (mono). The recognition sites for each of the antibodies selected for these experiments are distant from the catalytic domain and from Tyr402 to allow the structural flexibility that might be necessary for trans-autophosphorylation. Each of the three antibodies induced Pyk2 autophosphorylation in brain cytosol in the presence of Mg-ATP (Fig. 1C, lanes 3, 5, 7). Nonspecific antibodies did not lead to substantial autophosphorylation (lanes 1,8).

To further scrutinize this point, Pyk2 was immunoprecipitated with increasing amounts of $\alpha \mathrm{N}$ immobilized on protein $\mathrm{A}$ Sepharose before addition of aliquots of brain cytosolic extracts. Each aliquot contained $500 \mu \mathrm{g}$ of protein (Bradford protein as- say). After washing, samples were incubated with Mg-ATP and analyzed by immunoblotting (Fig. 1D). Probing for total Pyk2 shows that the amount of immunoprecipitated Pyk2 saturated at $\sim 0.25 \mu \mathrm{g}$ of $\alpha \mathrm{N}$ (middle panel), which completely removed Pyk2 from the cytosol samples (data not shown). Probing for the antibody light chain in the immunoprecipitates illustrates the increase in antibody (bottom panel). Probing for Tyr402 phosphorylation indicates that the total amount of phosphorylated Tyr402 initially increased in parallel with the amount of Pyk2 protein. However, beyond an optimal concentration at which Pyk 2 immunoprecipitation was saturated $(\sim 0.25$ $\mu \mathrm{g}$ of $\alpha \mathrm{N}$ ), Tyr402 phosphorylation rapidly decreased. This decrease must be attributable to a change in the Pyk2:antibody stoichiometry, being closest to the optimal 2:1 ratio at $\sim 0.25 \mu \mathrm{g}$ of $\alpha \mathrm{N}$ and reaching nearly 1:1 during additional increases of $\alpha \mathrm{N}$ because an excess of $\alpha \mathrm{N}$ increasingly promoted binding of one rather than two Pyk2 molecules per antibody complex. Accordingly, trans-autophosphorylation occurred at intermediate antibody concentrations when the amount of IgG-dimerized Pyk2 was highest. cis-autophosphorylation was not detectable as illustrated by the lack of autophosphorylation at higher $\alpha \mathrm{N}$ concentrations when individual Pyk2 molecules were on separate antibody complexes too far apart for trans-autophosphorylation. Finally, monoclonal anti-Pyk2 was treated with papain to produce Fab fragments, which are no longer linked together via the heavy chain disulfide bridge but rather constitute monomeric epitope binding sites. The Fab fragments were no longer capable of inducing Tyr402 phosphorylation in cytosolic solution when the same amount of untreated monoclonal antibody effectively induced Tyr402 phosphorylation as originally seen in Figure $1 C$ (data not illustrated).

It is theoretically possible that another kinase is stoichiometrically associated with Pyk2 in such a steric arrangement that enables such a hypothetical kinase to phosphorylate a second Pyk2 complex in trans but not the Pyk2 directly bound to it. However, silver staining for total protein in the Pyk2 immunoprecipitates only identified one main single band of the expected size of Pyk2 itself near the top of this relatively high-percentage gel (Fig. 1E) except for the heavy chain of the immunoprecipitating antibody. This band was absent in control immunoprecipitates, confirming its identity as being Pyk2. No other band was detectable, indicating that there is no other major protein precipitating with $\mathrm{Pyk} 2$ with a near stoichiometric relationship under basal conditions.

\section{Ectopic PSD-95 expression leads to Pyk2 activation}

Pyk2 binds to PSD-95 (Seabold et al., 2003), which is one of the most prominent scaffolding proteins at postsynaptic sites. 
PSD-95 can oligomerize via two mechanisms. One involves palmitoylation of the cysteine residues in position 3 and 5 near the $\mathrm{N}$ terminus of PSD-95 (Craven et al., 1999; El-Husseini Ael et al., 2002), although precisely how palmitoylation leads to PSD-95 oligomerize is unclear. The other is mediated by binding of the $\mathrm{SH} 3$ domain of one PSD-95 molecule to the GK domain of another PSD-95 molecule (Masuko et al., 1999; McGee and Bredt, 1999; Shin et al., 2000; McGee et al., 2001). We hypothesized that ectopic expression of PSD-95 fosters Pyk2 dimerization and thereby trans-autophosphorylation. We used PC6-3 cells, a subclone of PC12 cells (Pittman et al., 1993). PC12 cells are widely used for studying Pyk2 because of their high levels of endogenous Pyk2 and their similarity to neurons after treatment with nerve growth factor (Lev et al., 1995; Barsacchi et al., 1999; IvankovicDikic et al., 2000; Park et al., 2000; Haglund et al., 2004; Park et al., 2004; Banno et al., 2005). However, PC6-3 cells do not possess detectable levels of endogenous PSD-95 (data not shown). PC6-3 cells were transfected with either GFP or GFP and PSD-95. After $48 \mathrm{~h}$, immunoblotting of cell extracts showed that ectopic expression of PSD-95, but not GFP alone, induced Pyk2 Tyr402 phosphorylation without altering total Pyk2 levels (Fig. $1 F$ ). The most obvious explanation for this effect is that increased PSD-95 levels shift the equilibrium from free to PSD-95-bound Pyk2 under basal activity levels of the PC6-3 cells. In neurons, Pyk2 binding to PSD-95 and thereby Pyk2 autoactivation is triggered by influx of $\mathrm{Ca}^{2+}$, which acts in conjunction with calmodulin, as detailed below. However, PSD-95 overexpression in PC6-3 cells can lead to Pyk2 autoactivation without $\mathrm{Ca}^{2+}$ influx because Pyk2 binds even without $\mathrm{Ca}^{2+} /$ calmodulin to PSD-95, although this interaction is much weaker than if $\mathrm{Ca}^{2+} /$ calmodulin are present (see Fig. 3B, lanes 3-6). These findings thus indicate that Pyk2 binding to PSD-95 induces Pyk2 trans-autophosphorylation and thereby activation.

Notably, we also observed massive Tyr402 phosphorylation when Pyk2 was expressed in E. coli (Fig. 1G). Such an induction of tyrosine phosphorylation by ectopic expression of a tyrosine kinase in E. coli appears unusual. It is once more best explained by our model of transautophosphorylation of Pyk2 at elevated Pyk2 concentrations, which can lead to trans-autophosphorylation during Pyk2 overexpression in PC12 cells attributable to weak or transient direct or indirect interactions between individual Pyk2 molecules (Park et al., 2004).
A
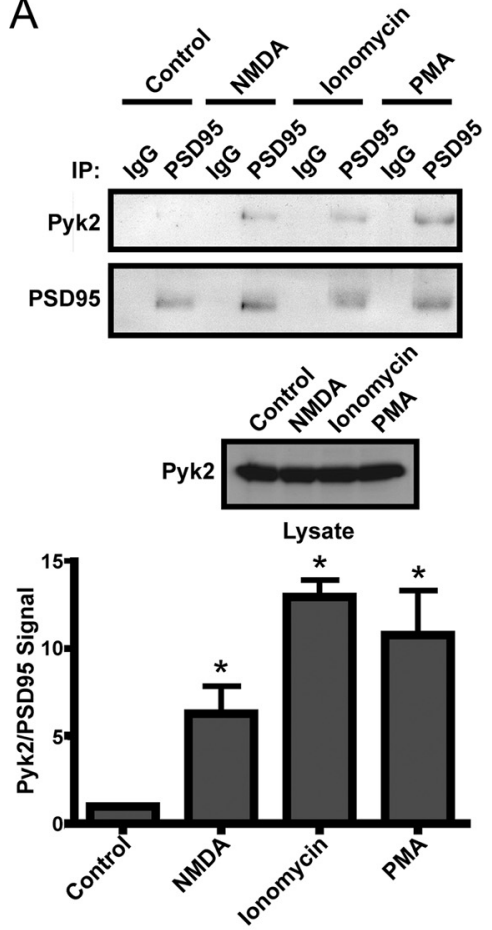

C
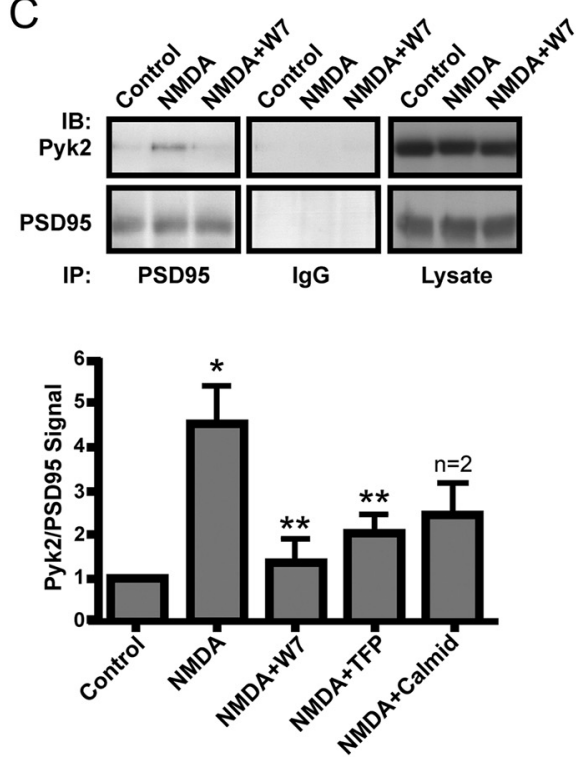

B
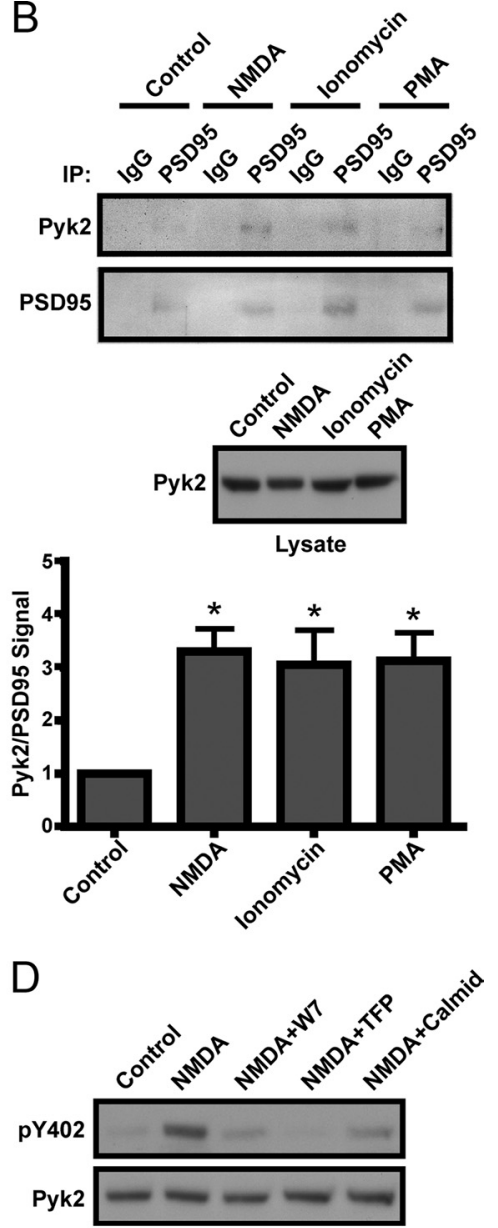

Figure 2. Stimulation of Pyk2 binding to PSD-95 and Pyk2 autophosphorylation in intact neurons. $\boldsymbol{A}, \boldsymbol{B}$, Acute cortical slices $(\boldsymbol{A})$ or primary hippocampal cultures ( $\boldsymbol{B}$; 18 DIV) were incubated with TTX (1 $\mu \mathrm{M})$ plus vehicle (Control), NMDA (50 $\mu \mathrm{M})$, ionomycin (1 $\mu \mathrm{M})$, or PMA (100 nM) for 15 min and extracted (1\% deoxycholate) before immunoprecipitation (IP) with control lgG and then anti-PSD-95. Immunoblots (IB) were probed with anti-PSD-95 and reprobed with monoclonal Pyk2 antibody (top). Immunosignals were quantified by film densitometry (bottom). Although the variability in PSD-95 precipitation was low, Pyk2 signals were corrected by dividing each Pyk2 signal by the corresponding PSD-95 signal. The Pyk2/PSD-95 ratio was normalized to control equaling 1. Immunoblotting of lysates illustrates that the same amounts of Pyk2 were present in all samples (middle). Stimulation with NMDA, ionomycin, or PMA induced a several fold increase in Pyk2 coimmunoprecipitation with PSD-95 in slices and cultures.

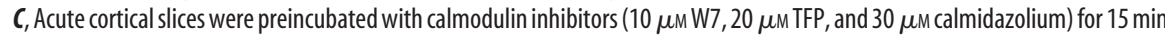
before incubation with TTX plus vehicle or NMDA, processing, and analysis as in $\boldsymbol{A}$. Control lgG precipitations (middle column) were from the same blots and exposures as PSD-95 precipitations (left column). All three calmodulin inhibitors prevented the NMDAinduced increase in coprecipitation of Pyk2 with PSD-95 (bottom row) without changing total Pyk2 in lysates (right column). D, Primary hippocampal cultures (18 DIV) were pretreated with calmodulin inhibitors before incubation with TTX plus vehicle or NMDA. Immunoblotting was performed on lysates with the phosphospecific antibody against Pyk2 Tyr402 (pY402) and, after stripping, monoclonal Pyk2 antibody. Signals were quantified by densitometry. The pY402/total Pyk2 ratio was normalized to control equaling 1. NMDA induced a several fold increase in Pyk2 Tyr402 phosphorylation, which was blocked by all three calmodulin antagonists. $\boldsymbol{A}-\boldsymbol{D}$, Asterisks indicate statistical significance compared with control $\left({ }^{*}\right)$ or NMDA $\left({ }^{* *}\right)$ treatment ( $t$ test, $p<0.05 ; n=4 \pm$ SEM for all experiments). 

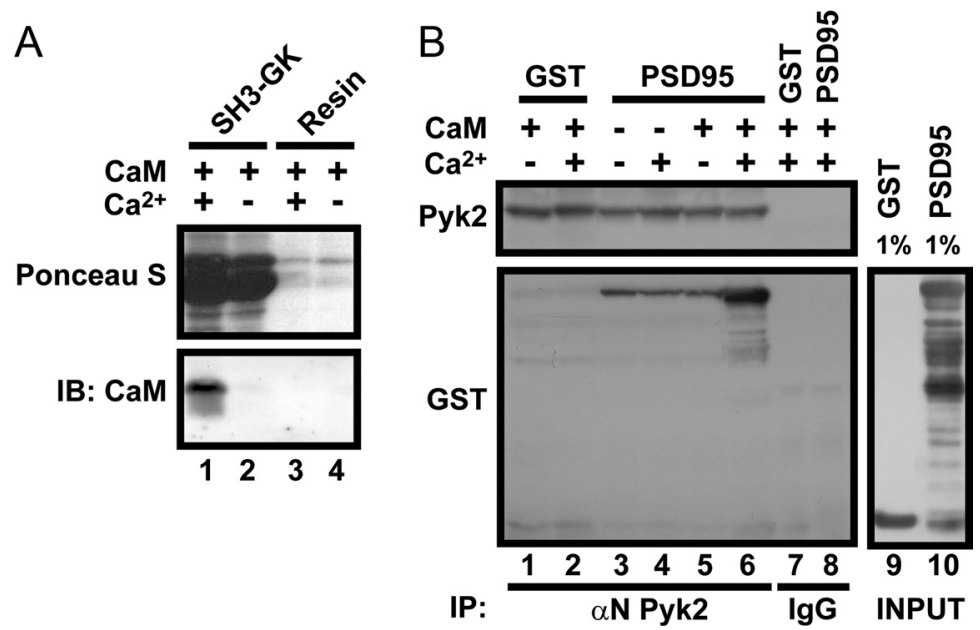

Figure 3. $\mathrm{Ca}^{2+} / \mathrm{calmodulin}$ stimulates PSD-95 binding to Pyk2. $A, \mathrm{Ni}^{2+}$-agarose was incubated with or without the bacterially expressed His-tagged SH3-GK module of PSD-95 and subsequently with calmodulin $(10 \mu \mathrm{M})$ in the presence and absence of $\mathrm{Ca}^{2+}$ $(10 \mathrm{~mm})$ before immunoblotting (IB). Ponceau S staining indicates immobilization of SH3-GK (lanes 1, 2). Probing with anticalmodulin antibodies shows specific calmodulin binding to the SH3-GK domain when $\mathrm{Ca}^{2+}$ is present. $\boldsymbol{B}$, Bacterially expressed Pyk2 was immunoprecipitated (IP) using $\alpha \mathrm{N}$ Pyk2 (lanes 1-6) or, as negative control, nonspecific rabbit lgG (lanes 7, 8) before incubation with GST or full-length PSD-95-GST with and without $\mathrm{Ca}^{2+}(10 \mathrm{mM})$ and calmodulin $(10 \mu \mathrm{M})$ as indicated. Samples were washed with and without $\mathrm{Ca}^{2+}$ corresponding to the binding incubation conditions. Samples underwent immunoblotting with monoclonal Pyk2 and subsequently GST antibodies. GST-PSD-95 (lanes 3-6) but not GST alone (lanes 1, 2) bound to Pyk2. This interaction was increased in the presence of $\mathrm{Ca}^{2+}$ and calmodulin (lane 6). Lanes 9 and 10 show immunoblots with anti-GST of input material. GST-PSD-95 was partially degraded at the ( terminus (GST resided at the $\mathrm{N}$ terminus). The lack of binding of the truncated polypeptide in the middle region but not the top one-third of the gel (compare lane 10 with lane 6) is consistent with proteolytic removal of SH3 in the more extensively truncated form of GST-PSD-95.

\section{$\mathrm{Ca}^{2+}$ influx and stimulation of PKC induce Pyk2 binding to PSD-95}

Based on the above results (Fig. 1), we hypothesized that treatment with pharmacological agents known to activate Pyk2 would do so by inducing its clustering. In neurons, such clustering could be accomplished by binding to PSD-95. After a 5 min pretreatment with the $\mathrm{Na}^{+}$channel blocker TTX to prevent action potentials and thereby overexcitation (Hell et al., 1996; Leonard et al., 1999), acute cortical slices and primary hippocampal cultures were incubated with vehicle, the NMDAR agonist NMDA (to selectively induce $\mathrm{Ca}^{2+}$ influx through NMDARs), the $\mathrm{Ca}^{2+}$ ionophore ionomycin, or the PKC activator PMA (for more details and discussion of the use of these drugs see, Materials and Methods). Slices and cultures were then extracted with $1 \%$ deoxycholate before sequential immunoprecipitation with nonspecific control IgG and anti-PSD-95 and immunoblotting with anti-Pyk2 and subsequently anti-PSD-95. NMDA, ionomycin, and PMA increased coimmunoprecipitation of Pyk2 with PSD-95 several fold in both systems compared with vehicle control (Fig. $2 A, B$ ). None of the treatments affected the total amount of Pyk2 present in tissue or culture lysates (Fig. $2 A, B$ ). Immunoprecipitation with nonspecific IgG resulted in no signal, ensuring that immunoprecipitation of PSD-95 and the associated Pyk2 was specific.

\section{NMDA-induced Pyk2 association with PSD-95 and Pyk2 autophosphorylation requires calmodulin}

There is good evidence that $\mathrm{Ca}^{2+} /$ calmodulin mediates activation of Pyk2 in vitro (Kohno et al., 2008). Furthermore, calmodulin has been implicated previously in Pyk2 signaling. For instance, $\alpha 1 \mathrm{~b}$ and $\alpha 2 \mathrm{a}$ adrenergic receptor-triggered ERK1/2 phosphorylation was antagonized by dominant-negative Pyk2 and Src and by three different calmodulin inhibitors (Della Rocca et al., 1997). Similarly, upregulation of NMDAR currents and the correlated tyrosine phosphorylation of the NMDAR, Pyk2, and Src required $\mathrm{Ca}^{2+} /$ calmodulin when induced by stimulation of the metabotropic glutamate receptor mGluR1 (Heidinger et al., 2002). Interestingly, PKC inhibitors had no effect in these studies, pointing toward release of $\mathrm{Ca}^{2+}$ from intracellular stores as the main signaling mechanism in these two cases. We hypothesized that inhibition of calmodulin would reduce NMDAR-mediated Pyk2 binding to PSD95. Acute cortical slices were pretreated with three different calmodulin inhibitors (W7, TFP, or calmidazolium) for $15 \mathrm{~min}$ before TTX was added for an additional $15 \mathrm{~min}$ and ultimately NMDA or vehicle for the final 15 min treatment. All three calmodulin inhibitors antagonized the NMDA-induced Pyk2 coimmunoprecipitation with PSD-95 (Fig. 2C) without affecting the cellular levels of Pyk2 (for more details on the calmodulin inhibitors, see Materials and Methods).

Pyk2 activation was monitored by measuring phosphorylation of Tyr402. This phosphorylation is induced by $\mathrm{Ca}^{2+}$ influx through NMDARs in response to ischemia (Huang et al., 2001; Guo et al., 2004). Primary hippocampal cultures (18 DIV) were pretreated with vehicle or calmodulin antagonists before incubation with vehicle or NMDA. NMDA induced a sixfold increase in Tyr402 autophosphorylation (Fig. 2D). All three calmodulin antagonists blocked this increase in Pyk2 autophosphorylation (Fig. 2D) similar to their blockade of NMDAstimulated Pyk2 coprecipitation with PSD-95 (Fig. 2C).

\section{$\mathrm{Ca}^{2+} /$ calmodulin increases binding between Pyk2 and} PSD-95 in vitro

The SH3 domain of PSD-95 binds to Pyk2 residues 671-875, which include two proline-rich regions (Seabold et al., 2003). Calmodulin interacts in a $\mathrm{Ca}^{2+}$-dependent manner with the HOOK region of PSD-95 and its homologues SAP97 and SAP102 immediately adjacent to the SH3 domain (Masuko et al., 1999; Paarmann et al., 2002; Fukunaga et al., 2005). $\mathrm{Ca}^{2+} /$ calmodulin induces binding of the SH3 domain of SAP102 with the GK domain of PSD-95 (Masuko et al., 1999), possibly by loosening the intramolecular interaction between the SH3 and GK domains of these two proteins (McGee and Bredt, 1999; McGee et al., 2001). We found that $\mathrm{Ca}^{2+} /$ calmodulin but not calmodulin alone associates with the SH3-GK region of PSD-95 (Fig. 3A). We then tested whether $\mathrm{Ca}^{2+} /$ calmodulin can stimulate the interaction between PSD-95 and Pyk2. For this purpose, His-tagged fulllength Pyk2(1-1009) was expressed in E. coli. After immunoprecipitation from the bacterial extracts with the $\alpha \mathrm{N}$ Pyk 2 antibody or nonspecific IgG as negative control, the resin samples with the Pyk2 immunocomplexes were incubated with bacterially expressed GST-PSD-95 or GST alone in the presence or absence of $\mathrm{Ca}^{2+}$ and calmodulin. GST-PSD-95 bound specifically to Pyk2 after its immunoprecipitation with $\alpha \mathrm{N}$ (Fig. 3B, lanes 3-6). No binding was observed between GST-PSD-95 and control IgG precipitates (lane 8) or between $\alpha \mathrm{N}$ precipitates and GST (lanes $1,2)$, indicating the specificity of the GST-PSD-95 binding to 

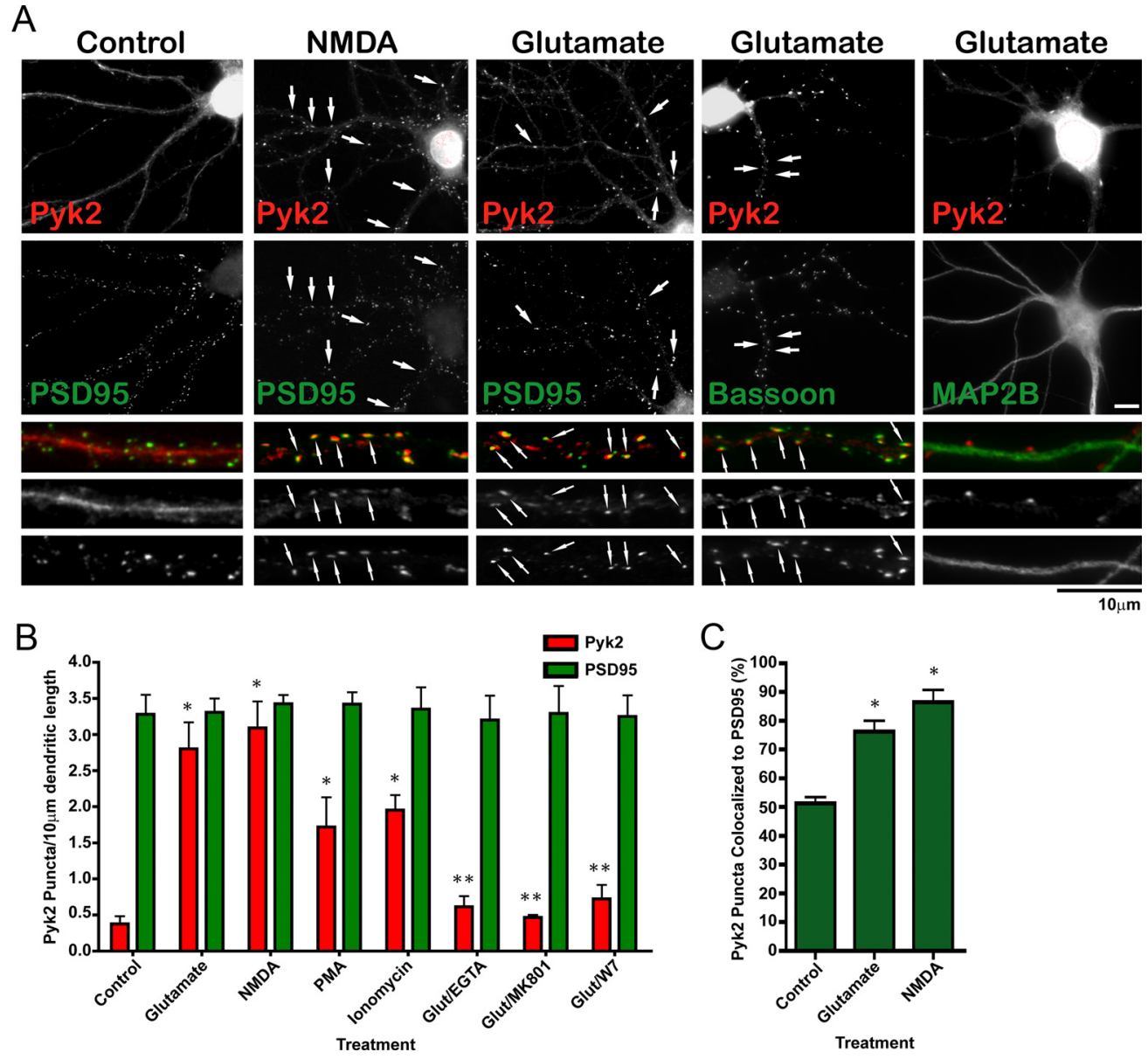

Figure 4. Stimulation-induced synaptic clustering of Pyk2 in hippocampal neurons. A, Primary hippocampal cultures ( $18 \mathrm{DIV}$ ) were treated with TTX ( $100 \mathrm{~nm})$ plus vehicle or glutamate ( $100 \mu \mathrm{M}$ ) for $15 \mathrm{~min}$ or NMDA $(50 \mu \mathrm{M})$ for $5 \mathrm{~min}$, fixed, and stained with $\alpha \mathrm{N}$ Pyk2 (red in overlay at higher magnification at bottom) plus PSD-95, bassoon, or MAP2B antibodies (green). Scale bars at bottom right represent $10 \mu \mathrm{m}$ for the corresponding magnifications. Arrows indicate Pyk2 puncta that colocalize with PSD-95 or bassoon puncta after stimulation. $\boldsymbol{B}$, Density of Pyk2 and PSD-95 immunoreactive puncta during treatment with TTX plus vehicle, glutamate (100 $\mu \mathrm{M}), \operatorname{PMA}(100 \mathrm{~nm})$, ionomycin (1 $\mu \mathrm{M}), \operatorname{NMDA}(50 \mu \mathrm{M})$, glutamate plus EGTA (2 mM), glutamate plus MK801 (10 $\mu \mathrm{m})$, or glutamate plus W7 (10 $\mu \mathrm{m}$ ) for $15 \mathrm{~min}$ (5 min for NMDA). C, Colocalization of Pyk2 puncta with PSD-95 puncta indicates that NMDA and glutamate stimulated Pyk2 clustering preferentially at synaptic PSD-95 clusters. A-C, For each experiment, three independent repetitions were performed except for the costaining of Pyk2 with bassoon and with MAP2B after glutamate treatment, which were only performed twice (but see Fig. 5). For quantifications shown in $\boldsymbol{B}$ and $\boldsymbol{C}, 5-12$ different fields were analyzed for each experiment, and values were averaged before statistical analysis for the means from the three independent experiments (4 experiments for control, glutamate, and NMDA treatments). Asterisks indicate significant differences compared with control (*) or glutamate $(* *)$ treatment $(t$ test, $p<0.05$; error bars indicate SEM). Both scale bars are $10 \mu \mathrm{m}$.

immunoisolated Pyk2. $\mathrm{Ca}^{2+} /$ calmodulin in combination, but not individually, strongly increased PSD-95 binding to Pyk2 (compare lane 6 with lanes 3-5). Importantly, both calmodulin binding to PSD-95 and the calmodulin-induced stimulation of Pyk2 binding to PSD-95 was $\mathrm{Ca}^{2+}$ dependent.

\section{$\mathrm{Ca}^{2+}$ influx through the NMDAR induces Pyk2 clustering at synapses}

Biochemical data described above raise the possibility that an increase in intracellular $\mathrm{Ca}^{2+}$ will induce Pyk2 translocation to postsynaptic sites in which PSD-95 is concentrated (Hunt et al., 1996; Rao et al., 1998; Valtschanoff and Weinberg, 2001; Sans et al., 2005). Mature (18 DIV) primary hippocampal cultures were pretreated with TTX, followed by stimulation for $15 \mathrm{~min}$ with vehicle or glutamate or for 5 min with NMDA. In subsequent studies, cultures received $30 \mathrm{~min}$ pretreatment with vehicle, EGTA to chelate extracellular $\mathrm{Ca}^{2+}$, MK801 to block NMDARs, or W7 followed by treatment with vehicle, glutamate, NMDA, PMA, or ionomycin as described above. Cultures were fixed immediately after stimulation and double labeled with $\alpha \mathrm{N}$ Pyk2 antibody and one of the following: anti-PSD-95, anti-bassoon, or anti-MAP2B antibodies (Fig. 4).

Under control conditions, Pyk2 was predominantly smoothly distributed throughout the somata and dendrites (Fig. 4A, top left panel). Glutamate and NMDA induced a dramatic redistribution of Pyk2 to a mainly punctate appearance as expected if synaptically targeted. Quantification of Pyk2 puncta per dendritic length indicates a near sevenfold increase in Pyk2 cluster density during glutamate and NMDA application (per $10 \mu \mathrm{m}$ dendritic length from $0.4 \pm 0.11$ in control to $2.8 \pm 0.37$ and $3.1 \pm 0.37$ in glutamate- and NMDA-treated neurons, respectively) (Fig. $4 B$ ). These puncta were chiefly colocalized with PSD-95 (Fig. 4A,C) and bassoon (Fig. 4A) particularly after glutamate and NMDA application. Bassoon is a well established specific marker for presynaptic active zones at mature synapses (Friedman et al., 2000; Zhai et al., 2001; Altrock et al., 2003; Shapira et al., 2003). Staining of parallel cultures for the microtubule-associated protein MAP2B, a dendritic marker (Hirokawa et al., 1988; Goedert et al., 1991), shows that the integrity of the dendrites was not affected by glutamate (Fig. $4 \mathrm{~A}$, 

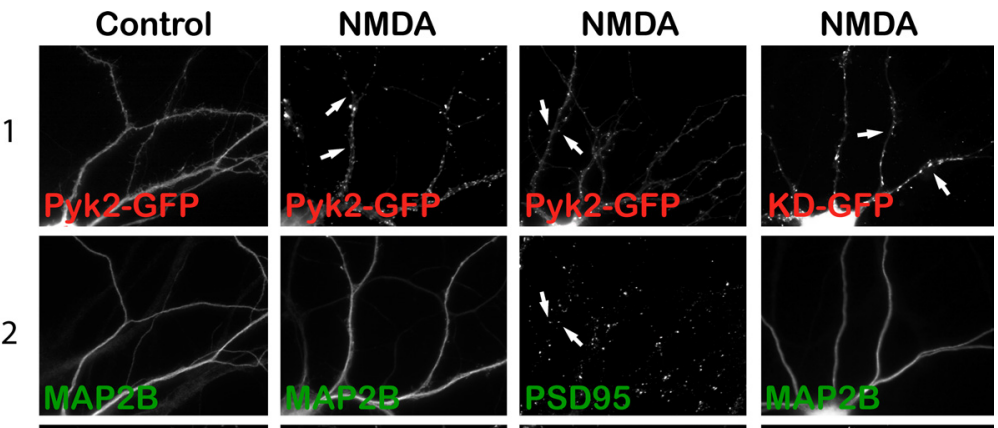

3
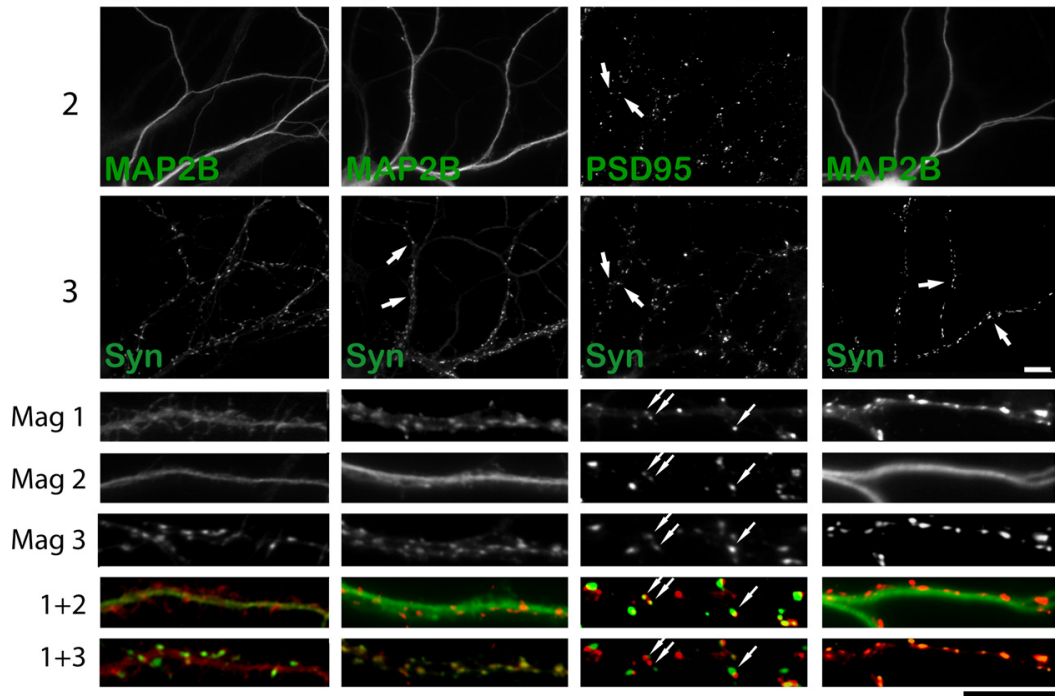

Figure 5. NMDA-induced Pyk2-GFP clustering occurs postsynaptically and independently of Pyk2 kinase activity. Primary hippocampal cultures (15 DIV) were transfected with Pyk2-GFP or GFP-tagged kinase-dead Pyk2 (KD-GFP) (72 h; red in all overlays at higher magnification at bottom), treated with TTX plus either vehicle or NMDA (50 $\mu \mathrm{m}, 5 \mathrm{~min}$ ), fixed, and stained with antibodies against synapsin (green in all dual overlays at the very bottom labeled " $1+3^{\prime \prime}$ ) and either MAP2B or PSD-95 (green in the respective overlays in the row labeled " $1+2$ "). Scale bars, $10 \mu \mathrm{m}$ for the corresponding magnifications. Pyk2-GFP underwent a dramatic relocation from a fairly smooth distribution under control conditions in dendritic shafts that was primarily colocalized with MAP2B to a pronounced punctate synaptic distribution away from MAP2B staining in dendritic shafts. Arrows illustrate examples of colocalization of Pyk2 and PSD-95 puncta that are juxtaposed to synapsin puncta. Kinase-dead Pyk2 also clusters during NMDA stimulation (right column). All pictures are representatives from three independent experiments.

Cultures were at low density, with the average distance between neighboring somata being $200 \mu \mathrm{m}$. After $3 \mathrm{~d}$, neurons were pretreated with TTX, treated with vehicle or NMDA, fixed, and stained with anti-synapsin and either anti-MAP2B or anti-PSD-95 antibodies. Synapsin is a synaptic vesicle-associated protein that is concentrated presynaptically and serves, like bassoon, as a synaptic marker (De Camilli et al., 1983; Chin et al., 1995). Under control conditions, Pyk2-GFP was smoothly distributed throughout dendritic areas of transfected neurons as identified by MAP2B labeling (Fig. 5, left column). Stimulation with NMDA induced clustering of Pyk2GFP similar to that observed with endogenous Pyk2. This clustering was within the dendritic areas of transfected neurons that were identified as a result of Pyk2-GFP signals in somata from which the dendrites originated (Fig. 5). NMDA-induced Pyk2GFP clusters primarily colocalized with synapsin and PSD-95. Because in all analyzed samples no other neurons close enough to form axonal contacts with one of the Pyk2GFP-positive neurons were transfected with Pyk2-GFP, this clustering is attributable to Pyk2-GFP accumulation at postsynaptic sites. Transfected GFP alone did not cluster when stimulated with NMDA (Fig. 6A).

Mutating Lys457 to Ala in GFP-Pyk2 creates a kinase-dead isoform. Like wild type, GFP-Pyk2(K457A) also clustered at postsynaptic sites (Fig. 5). Accordingly,

right panels) or NMDA (Fig. 5, middle) application. GFPtransfected neurons also showed no change in dendritic morphology when stimulated with NMDA (Fig. 6A).

Chelating extracellular $\mathrm{Ca}^{2+}$ with EGTA, blocking NMDAR pores with MK801, or inhibiting calmodulin with W7 blocked Pyk2 clustering without affecting PSD-95 distribution (supplemental Fig. 1, available at www.jneurosci.org as supplemental material) (Fig. $4 B$ ). Ionomycin induced clustering similar to glutamate and NMDA (supplemental Fig. 1, available at www. jneurosci.org as supplemental material) (Fig. $4 \mathrm{~B}$ ). These results indicate that increasing intracellular $\mathrm{Ca}^{2+}$, either with a general $\mathrm{Ca}^{2+}$ ionophore, which presumably acts along the whole dendritic shaft, or specifically via NMDARs, is necessary and sufficient for stimulating Pyk2 clustering at synapses. The PKC activating PMA also induced Pyk2 clustering (supplemental Fig. 1, available at www.jneurosci.org as supplemental material) (Fig. $4 B$ ), in agreement with the above finding that PMA, like NMDA and ionomycin, stimulates Pyk2 binding to PSD-95. However, PMA-induced Pyk2 clustering and binding to PSD-95 might depend on a mechanism different from that underlying $\mathrm{Ca}^{2+}$ influx-induced Pyk2 clustering and PSD-95 binding and is therefore not within the scope of this work.

\section{NMDA induces postsynaptic Pyk2 clustering}

Pyk2 is present not only in dendrites but also in axons (Seabold et al., 2003). GFP-tagged Pyk2 was expressed in 15 DIV hippocampal cultures by low-efficiency calcium phosphate transfection so that only a few widely dispersed neurons expressed Pyk2-GFP. postsynaptic Pyk2 clustering is independent of its activity, consistent with our hypothesis that clustering precedes its activation.

\section{NMDA-induced Pyk2 clustering depends on the SH3 domain of PSD-95}

To address the role of PSD-95 in Pyk2 clustering, the GFP-tagged SH3 domain of PSD-95 was ectopically expressed in primary hippocampal cultures. Because Pyk2 interacts with the PSD-95 SH3 domain (Seabold et al., 2003), overexpression of the SH3 domain was hypothesized to disrupt the stimulation-dependent interaction between Pyk2 and synaptically localized PSD-95. In fact, NMDA stimulation was unable to initiate clustering of endogenous Pyk2 in the presence of SH3-GFP, whereas Pyk2 clustered readily in GFP-expressing neurons (Fig. 6A). The Pyk2 puncta density was threefold higher in GFP than in GFP-SH3transfected neurons when treated with NMDA $(2.7 \pm 0.26$ compared with $0.9 \pm 0.20$ ) (Fig. $6 B$ ). The Pyk2 puncta density of GFP-transfected neurons stimulated with NMDA was comparable with that of untransfected NMDA-stimulated neurons (Fig. $4 A, B)$. Endogenous PSD-95 was unaffected by expression of GFP or SH3 domain (Fig. 6A).

\section{NMDA-induced Pyk2 autophosphorylation depends on the SH3 domain of PSD-95}

Induction of Pyk 2 autoactivation and binding to PSD-95 in intact neurons show the same pharmacological profiles. We investigated whether Pyk2 binding to PSD-95 is required for NMDAinduced Pyk 2 activation with the hypothesis that inhibition of the 
Pyk2-PSD-95 interaction would eliminate Pyk2 activation by NMDA. Primary hippocampal cultures (15 DIV) were infected with the GFP-tagged PSD-95 SH3 domain similar to that used above, except a lentiviral vector based on a minimal FIV was used. This vector provided $>90 \%$ infection efficiency in hippocampal cultures without detectably affecting the health of the neurons. Control infections were performed with GFP alone expressed from an analogous FIV vector. At 18 DIV, the neurons were stimulated with NMDA in the presence of TTX and pervanadate. Lysates were analyzed by immunoblotting with phospho-Tyr402, monoclonal Pyk2, and GFP antibodies as before. The results clearly show that GFP-SH3 but not GFP alone suppresses the NMDA-induced upregulation of Pyk2 autophosphorylation (Fig. 6C,D).

\section{Binding of Pyk2 to PSD-95 is necessary for LTP}

We showed previously that the sequential activation of Pyk 2 and Src plays a critical role in the induction of LTP at CA3-CA1 synapses (Lu et al., 1998; Xiong et al., 1999; Huang et al., 2001; Salter and Kalia, 2004). To test the relevance of the interaction between Pyk2 and PSD-95 in LTP induction, whole-cell patch recordings were obtained from pyramidal neurons in the hippocampal CA1 region. Recording electrodes contained GST alone as control, the GST-tagged SH3 domain of PSD-95, or the GST-tagged Pyk2 residues 671-875, which mediate Pyk2 binding to the $\mathrm{SH} 3$ domain of PSD-95 (Seabold et al., 2003). None of the polypeptides affected basal NMDAR EPSCs, as measured with CNQX to block AMPARs (Fig. 7A,B), or NMDAevoked whole-cell currents (Fig. $7 C$ ) under basal conditions over a time course of 25-30 $\mathrm{min}$. This is consistent with our recent finding that, contrasting cultured neurons, in acute slices Src-mediated upregulation of NMDAR activity is constitutively suppressed under basal conditions by the Cterminal Src kinase CSK (Xu et al., 2008). However, the induction of LTP was entirely blocked by including either the SH3 domain of PSD-95 or the SH3 binding site on Pyk2 in the pipette, whereas GST by itself failed to block LTP (Fig. 7D-F). Currents were averaged 5 min before and $30 \mathrm{~min}$ after tetani. Potentiation under control conditions (GST) was $161 \pm 12 \%(p<0.001$ vs baseline $)$ compared with $92 \pm 0.06 \%$ for GST-SH3 ( $p<0.001$ vs control LTP) and $104 \pm 0.05 \%$ for GST-Pyk2(671-875) ( $p=0.004$ vs control LTP).

\section{Discussion}

Role of PSD-95 in postsynaptic clustering and activation of Pyk 2

Under basal conditions, PSD-95 is concentrated at postsynaptic sites, whereas Pyk2 is diffuse throughout dendrites. We hypothesize that the interaction between the $\mathrm{SH} 3$ and GK domain in the
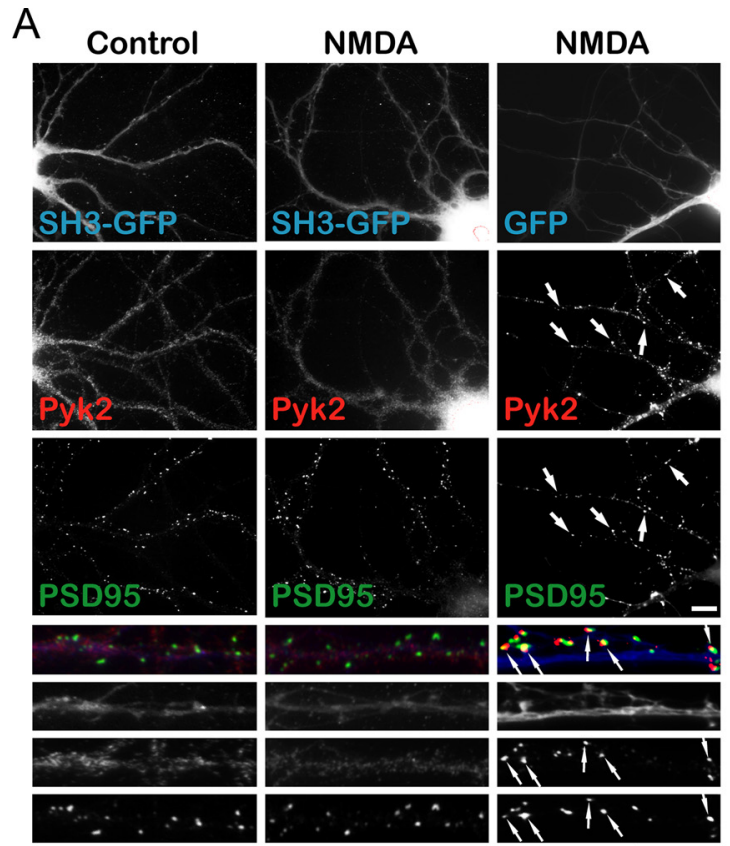

B
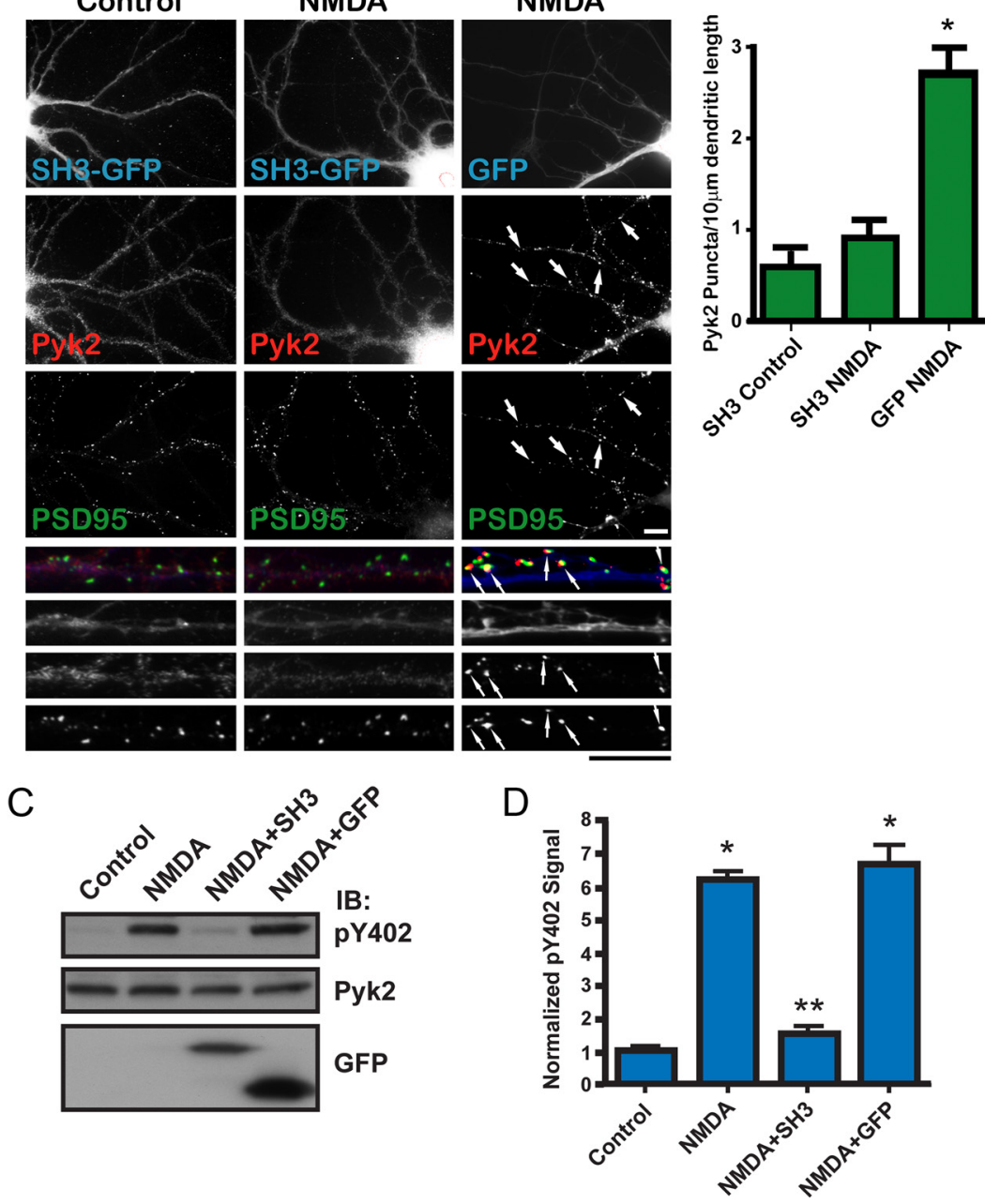

Figure 6. Overexpression of the PSD-95 SH3 domain inhibits NMDA-induced Pyk2 clustering and Pyk2 autophosphorylation. A, Primary hippocampal cultures (15 DIV) were transfected with the GFP-tagged SH3 domain of PSD-95 (SH3-GFP) or GFP alone (72 $\mathrm{h}$; blue in overlay at higher magnification at bottom), treated with TTX plus vehicle or NMDA ( $50 \mu \mathrm{m}, 5 \mathrm{~min})$, fixed, and stained with antibodies against endogenous Pyk2 ( $\alpha \mathrm{N}$; red in overlay) and PSD-95 (green in overlay). Scale bars, $10 \mu \mathrm{m}$ for the corresponding fGFP alone. Five to 10 different fields were analyzed for each experiment, and values were averaged before statistical analysis for the means from the three independent experiments. The asterisk indicates statistical significance in Pyk2 clustering in neurons fected with packaged FIV pVETL vectors encoding PSD-95 SH3-GFP or GFP alone (72 h) and treated with TTX plus pervanadate ( plus vehicle or NMDA (50 $\mu \mathrm{M}, 15 \mathrm{~min}$ ) before immunoblotting (IB) with anti-phospho-Tyr402, monoclonal Pyk2, and GFP antibodies. D, Immunosignals were quantified by film densitometry. The pY402/Pyk2 ratios were normalization to control equaling 1. Asterisks denote statistical significance compared with control $\left({ }^{*}\right)$ or NMDA plus GFP $\left.{ }^{* *}\right)(t$ test, $p<0.05 ; n=3 \pm \operatorname{SEM})$.

basal state of PSD-95 is responsible for inhibiting Pyk2 binding. $\mathrm{Ca}^{2+}$ induces calmodulin binding to the HOOK regions of PSD-95 and its homologs SAP97 and SAP102, which connect their SH3 and GK domains (Masuko et al., 1999; Paarmann et al., 2002; Fukunaga et al., 2005). $\mathrm{Ca}^{2+} /$ calmodulin binding results in a rearrangement, which likely includes displacement of the GK domain from the $\mathrm{SH} 3$ domain promoting Pyk2 binding to the $\mathrm{SH} 3$ domain. Pyk2 could consequently accumulate at postsynaptic sites, in which binding to PSD-95 clusters would mediate its oligomerization. This model is supported by the finding that PSD-95 and its homologs form homomultimers and heteromultimers (Tomita et al., 2001; Christopherson et al., 2003; Kim and Sheng, 2004). The proximity of Pyk 2 molecules could promote trans-autophosphorylation, thereby leading to Pyk2 activation. SAP97, SAP102, and the related CHAPSYN110/PSD-93 are 

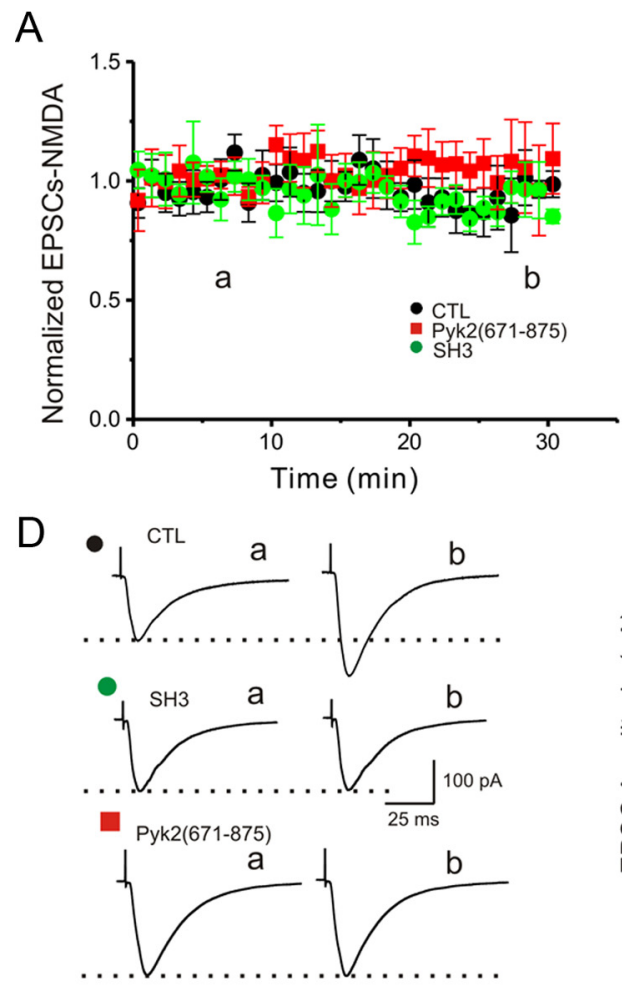

B

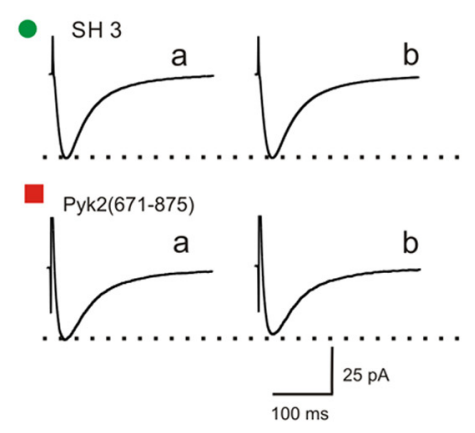

E

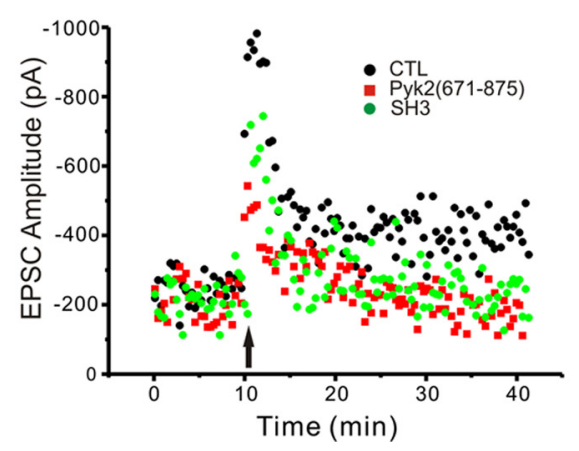

C

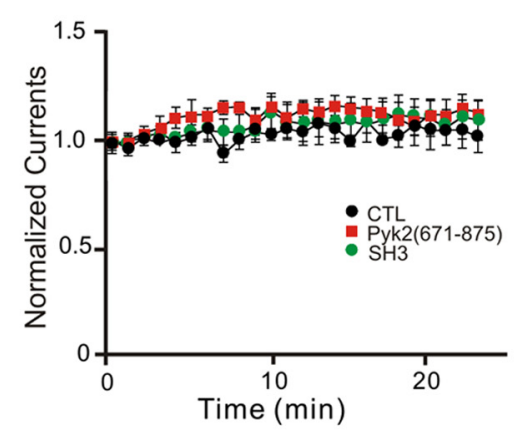

$\mathrm{F}$

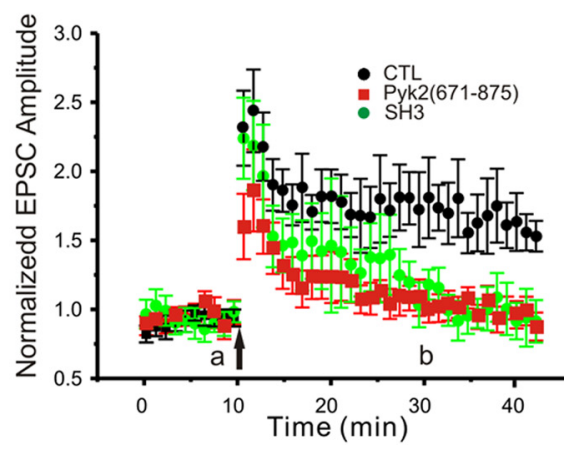

Figure 7. Interfering with the PSD-95-Pyk2 interaction prevents induction of LTP. $A, B$, Peak currents of NMDAR-mediated EPSCS in CA1 isolated with CNQX are not affected during infusion of GST ( $n=5$; (TL; black circles), GST-SH3 ( $n=3$; green circles), or GST-Pyk2 (671-875) ( $n=5$; red squares). C, NMDA-induced whole-cell patch peak currents in acutely isolated CA1 neurons are not affected during infusion of GST ( $n=7$; (TL; black circles), GST-SH3 ( $n=7$; green circles), or GST-Pyk2(671-875) $(n=6$; red squares). D-F, LTP induced by two tetani of $100 \mathrm{~Hz} / 500 \mathrm{~ms}, 10$ s apart, was blocked by infusion of GST-SH3 ( $n=6$; green circles) and GST-Pyk2 (671-875) ( $n=6$; red squares) but not GST alone ( $n=7$; CLT; black circles). Shown are sample traces (D) before (a) and 30 min after $(\boldsymbol{b})$ tetani, exemplary time courses for each condition $(\boldsymbol{E})$, and averaged EPSCs that were normalized to baseline for each experiment from all time courses for each condition \pm SEM $(\boldsymbol{F})$. Arrows indicate time of tetani.

present at postsynaptic sites and might also contribute to Pyk2 clustering and activation. However, PSD-95 is the functionally prevailing postsynaptic representative of this protein family in hippocampal neurons (Schlüter et al., 2006).

Precise localization of kinases is important for effective and specific phosphorylation of targets (Pawson and Scott, 1997; Wong and Scott, 2004). CaMKII translocates to postsynaptic sites during $\mathrm{Ca}^{2+}$ influx through NMDAR binding (Leonard et al., 1999; Shen and Meyer, 1999; Bayer et al., 2001; Merrill et al., 2005) for postsynaptic signaling (Barria and Malinow, 2005). We now demonstrate the postsynaptic translocation of Pyk2 during NMDAR-mediated $\mathrm{Ca}^{2+}$ influx (Figs. 4,5). Ectopic expression of PSD-95 SH3-GFP prevented postsynaptic Pyk2 clustering, indicating that this clustering is via Pyk2 binding to PSD-95 or homologs (Fig. 6).

Dimerization by antibodies in vitro and overexpression of PSD-95 in PC6-3 cells induce trans-autophosphorylation of Pyk2, indicating that PSD-95 binding promotes Pyk2 activation by oligomerization (Fig. 1). $\mathrm{Ca}^{2+}$ influx through NMDAR stimulates coimmunoprecipitation of Pyk2 with PSD-95 and concomitant Pyk2 Tyr402 autophosphorylation (Figs. 2, 3, 6). GFP-SH3 completely blocked activity-induced Pyk2 autophosphorylation, indicating that the autoactivation depends on access to the $\mathrm{SH} 3$ domain of PSD-95 (Fig. 6).

\section{Role of $\mathrm{Ca}^{2+} /$ calmodulin and PKC}

$\mathrm{Ca}^{2+} /$ calmodulin stimulates Pyk2 binding to PSD-95 (Figs. 2C, 3) and Pyk2 trans-autophosphorylation (Fig. 2D), consistent with the finding that calmodulin only interacts with PSD-95 and
SAP102 when $\mathrm{Ca}^{2+}$ is present (Masuko et al., 1999; Paarmann et al., 2002; Fukunaga et al., 2005). $\mathrm{Ca}^{2+} /$ calmodulin is also critical for postsynaptic Pyk2 clustering during $\mathrm{Ca}^{2+}$ influx through the NMDAR (Fig. 4B). PKC inhibitors did not inhibit glutamate- or NMDA-induced Pyk2 clustering (data not shown), suggesting that $\mathrm{PKC}$ is not necessary for postsynaptic Pyk2 clustering and activation induced by $\mathrm{Ca}^{2+}$ influx.

However, stimulation of PKC also led to PSD-95 binding (Fig. 2) and postsynaptic Pyk2 clustering (Fig. 4). PSD-95 binding might thus be a general mechanism for Pyk2 activation in neurons. One isoform of PKC (PKC $\alpha$ ) binds PSD-95 (Lim et al., 2002). NMDAR-mediated $\mathrm{Ca}^{2+}$ influx can activate the $\mathrm{Ca}^{2+}$ sensitive phospholipase C $\delta$ (Rebecchi and Pentyala, 2000) for production of PKC-activating diacylglycerol compounds in neurons (Codazzi et al., 2006). Nevertheless, additional characterization of this PKC-mediated mechanism is beyond the scope of this article.

We do not know at this point with certainty how $\mathrm{Ca}^{2+} / \mathrm{cal}$ modulin induces Pyk2/PSD-95 association. Because $\mathrm{Ca}^{2+} / \mathrm{cal}-$ modulin can regulate the SH3-GK domain interaction, we hypothesize that $\mathrm{Ca}^{2+} /$ calmodulin is promoting Pyk2 binding to PSD-95 by relaxing the intramolecular interaction between $\mathrm{SH} 3$ and GK of PSD-95 (Masuko et al., 1999; McGee and Bredt, 1999; McGee et al., 2001). Once bound to PSD-95, which forms dimers (Craven et al., 1999; Masuko et al., 1999; Shin et al., 2000; McGee et al., 2001; El-Husseini Ael et al., 2002) and perhaps oligomers at postsynaptic sites, Pyk2 proteins within a complex could transautophosphorylate, thereby conferring activation (Fig. $1 F$ ).

$\mathrm{Ca}^{2+}$ /calmodulin might also directly bind to Pyk2 for its activation (Kohno et al., 2008). However, the involvement of inter- 
mediary proteins, possibly PSD-95 homologs that are present in non-neuronal cells such as SAP97, has not been excluded in this work. Based on point mutations, the authors propose that $\mathrm{Ca}^{2+}$ / calmodulin binds to a segment in the middle of the FERM domain. However, this segment is essentially buried in the crystal structure of FAK (Lietha et al., 2007) and likely not accessible to $\mathrm{Ca}^{2+} /$ calmodulin (Schaller, 2008).

$\mathrm{Ca}^{2+} /$ calmodulin is also important for CaMKII binding to the NMDAR NR2B subunit (Bayer et al., 2001; Leonard et al., 2002). This $\mathrm{Ca}^{2+} /$ calmodulin-induced binding promotes autophosphorylation between subunits of the dodecameric CaMKII holoenzyme (Bayer et al., 2001; Merrill et al., 2005) (see also Sun et al., 2004). Calmodulin thus emerges as a key mediator of recruiting and regulating postsynaptic signaling elements at activated postsynaptic sites. KN93 (2-[N-(2-hydroxyethyl)]-N-(4-methoxybenzenesulfonyl)amino- $N$-(4-chlorocinnamyl)- $N$-methylbenzylamine), which inhibits $\mathrm{Ca}^{2+} /$ calmodulin-dependent kinases including CaMKII, failed to affect glutamate-induced Pyk2 clustering, indicating that the effects of $\mathrm{Ca}^{2+} /$ calmodulin were independent of CaMKII (data not shown).

\section{Role of Src in Pyk2 signaling}

Pyk2 stimulates the NMDAR activity through Src, which acts downstream of Pyk2 at postsynaptic sites (Yu et al., 1997; Lu et al., 1998; Huang et al., 2001; Salter and Kalia, 2004) (see also Corvol et al., 2005). However, in some non-neuronal cells, the initial $\mathrm{Ca}^{2+}$-dependent Pyk2 activation through Tyr402 autophosphorylation is inhibited, although not fully blocked, by Src antagonists (Sorokin et al., 2001; Cheng et al., 2002). These results suggest that interdependence between Pyk2 and Src activation can exist. Autophosphorylation of Pyk2 on Tyr402 recruits and activates Src for additional phosphorylation and additional activation of Pyk2 (see Introduction). It is obvious that Src binding to phosphorylated Tyr402 would protect Tyr402 from dephosphorylation, although this possibility is untested because the relevant phosphatase is unknown. Furthermore, the Src-mediated increase in Pyk2 activity would allow more effective rephosphorylation of Tyr402 should a Tyr402 residue in an oligomeric complex become dephosphorylated. These properties provide a positive feedback loop that prolongs the activity of Pyk2/Src complexes. Such complexes thus might constitute a molecular memory, which might be important for the establishment of LTP.

\section{Physiological relevance of Pyk2 clustering in LTP}

PKC increases NMDAR currents by stimulating Pyk2. Pyk2 then activates Src, which then phosphorylates NMDARs (Yu et al., 1997; Lu et al., 1998; Huang et al., 2001; Salter and Kalia, 2004). The PKC effect is blocked by injection of kinase-dead Pyk2 and various Src inhibitors. Src inhibitors but not PKC inhibitors block upregulation of NMDAR currents after injection of active Pyk2. Inhibition of PKC or Pyk2 activity does not affect upregulation of NMDAR activity by Src activators, placing Pyk2 downstream of PKC and upstream of Src. The PKC-Pyk2-Src signaling cascade is required for LTP in the hippocampal CA1 region (Yu et al., 1997; Lu et al., 1998; Huang et al., 2001; Salter and Kalia, 2004). We find that two different constructs that interfere with Pyk2 binding to PSD-95, GST-SH3 and Pyk2 residues 671-875, blocked LTP without directly affecting NMDAR function (Fig. 7). Because an increasing body of evidence indicates that LTP is the physiological correlate of learning and memory (Martin et al., 2000; Bredt and Nicoll, 2003; Collingridge et al., 2004; Malenka and Bear, 2004; Pastalkova et al., 2006; Whitlock et al., 2006), Pyk2 anchoring by PSD-95 is likely important for these higher brain functions.
The concomitant postsynaptic recruitment and activation of Pyk2 during NMDAR-mediated $\mathrm{Ca}^{2+}$ influx is an economical and effective mechanism to elevate Pyk2 activity, specifically at those synapses experiencing LTP. This targeting mechanism will ensure that Pyk2 is mainly active at those synapses undergoing potentiation. By providing for accumulation of Pyk 2 specifically at activated postsynaptic sites, this mechanism likely contributes to the critical synapse specificity of LTP, which is crucial for preventing saturation of neuronal input.

LTP at mossy fiber synapses in the hippocampal CA3 area is NMDAR independent and attributable to increased presynaptic glutamate release. However, postsynaptic NMDARs at CA2 mossy fiber synapses can undergo LTP themselves independent of increased glutamate release (Kwon and Castillo, 2008; Rebola et al., 2008). This NMDAR LTP requires coactivation of NMDAR and mGluR5 and the ensuing stimulation of PKC and Src, suggesting a PKC-Pyk2-Src-NMDAR cascade analogous to that established for CA1 synapses.

\section{Clinical aspects of Pyk 2 clustering in ischemia}

Ischemia causes reversal of glutamate transporters and overstimulation of NMDAR-mediated $\mathrm{Ca}^{2+}$ influx triggering neuronal damage (Rothman and Olney, 1987; Lee et al., 1999). Pyk2 translocates to postsynaptic densities after ischemia, in which it interacts with NMDARs via PSD-95 (Liu et al., 2001; Cheung et al., 2003; Seabold et al., 2003; Hou et al., 2005). NMDAR antagonists inhibit ischemia-induced stimulation of Pyk2, Src, and tyrosine phosphorylation of NR2A and NR2B (Liu et al., 2001; Guo et al., 2004). Hence, ischemia likely activates Pyk2 through PSD-95, which could contribute to consequent neuropathologies.

In summary, Pyk2 oligomerization in general and specifically by $\mathrm{Ca}^{2+} /$ calmodulin-induced PSD-95 binding in neurons induces its activation by trans-autophosphorylation. The concomitant postsynaptic Pyk2 accumulation at synapses undergoing potentiation allows for synapse-selective targeting and activation Pyk2, which contributes to the synapse-selective upregulation of NMDAR activity and thereby induction of LTP.

\section{References}

Ahmed R, Zha XM, Green SH, Dailey ME (2006) Synaptic activity and F-actin coordinately regulate CaMKIIalpha localization to dendritic postsynaptic sites in developing hippocampal slices. Mol Cell Neurosci 31:37-51.

Akyol Z, Bartos JA, Merrill MA, Faga LA, Jaren OR, Shea MA, Hell JW (2004) Apo-calmodulin binds with its C-terminal domain to the N-methyl-Daspartate receptor NR1 C0 region. J Biol Chem 279:2166-2175.

Altrock WD, tom Dieck S, Sokolov M, Meyer AC, Sigler A, Brakebusch C, Fässler R, Richter K, Boeckers TM, Potschka H, Brandt C, Löscher W, Grimberg D, Dresbach T, Hempelmann A, Hassan H, Balschun D, Frey JU, Brandstätter JH, Garner CC, Rosenmund C, Gundelfinger ED (2003) Functional inactivation of a fraction of excitatory synapses in mice deficient for the active zone protein bassoon. Neuron 37:787-800.

Avraham H, Park SY, Schinkmann K, Avraham S (2000) RAFTK/Pyk2mediated cellular signalling. Cell Signal 12:123-133.

Avraham S, London R, Fu Y, Ota S, Hiregowdara D, Li J, Jiang S, Pasztor LM, White RA, Groopman JE, Avraham H (1995) Identification and characterization of a novel related adhesion focal tyrosine kinase (RAFTK) from megakaryocytes and brain. J Biol Chem 270:27742-27751.

Banno Y, Ohguchi K, Matsumoto N, Koda M, Ueda M, Hara A, Dikic I, Nozawa Y (2005) Implication of phospholipase D2 in oxidant-induced phosphoinositide 3-kinase signaling via Pyk2 activation in PC12 cells. J Biol Chem 280:16319-16324.

Barria A, Malinow R (2005) NMDA receptor subunit composition controls synaptic plasticity by regulating binding to CaMKII. Neuron 48:289-301.

Barsacchi R, Heider H, Girault J, Meldolesi J (1999) Requirement of pyk2 for the activation of the MAP kinase cascade induced by $\mathrm{Ca}^{2+}$ (but not by PKC or G protein) in PC12 cells. FEBS Lett 461:273-276. 
Bayer KU, De Koninck P, Leonard AS, Hell JW, Schulman H (2001) Interaction with the NMDA receptor locks CaMKII in an active conformation. Nature 411:801-805.

Bredt DS, Nicoll RA (2003) AMPA receptor trafficking at excitatory synapses. Neuron 40:361-379.

Brewer GJ, Torricelli JR, Evege EK, Price PJ (1993) Optimized survival of hippocampal neurons in B27-supplemented Neurobasal, a new serumfree medium combination. J Neurosci Res 35:567-576.

Byron KL, Lucchesi PA (2002) Signal transduction of physiological concentrations of vasopressin in A7r5 vascular smooth muscle cells. A role for PYK2 and tyrosine phosphorylation of $\mathrm{K}^{+}$channels in the stimulation of $\mathrm{Ca}^{2+}$ spiking. J Biol Chem 277:7298-7307.

Chen C, Leonard JP (1996) Protein tyrosine kinase-mediated potentiation of currents from cloned NMDA receptors. J Neurochem 67:194-200.

Chen Y, Stevens B, Chang J, Milbrandt J, Barres BA, Hell JW (2008) NS21: re-defined and modified supplement B27 for neuronal cultures. J Neurosci Methods 171:239-247.

Cheng JJ, Chao YJ, Wang DL (2002) Cyclic strain activates redox-sensitive proline-rich tyrosine kinase 2 (PYK2) in endothelial cells. J Biol Chem 277:48152-48157.

Cheung HH, Teves L, Wallace MC, Gurd JW (2003) Inhibition of protein kinase $\mathrm{C}$ reduces ischemia-induced tyrosine phosphorylation of the $\mathrm{N}$-methyl-D-aspartate receptor. J Neurochem 86:1441-1449.

Chin LS, Li L, Ferreira A, Kosik KS, Greengard P (1995) Impairment of axonal development and of synaptogenesis in hippocampal neurons of synapsin I-deficient mice. Proc Natl Acad Sci U S A 92:9230-9234.

Christopherson KS, Sweeney NT, Craven SE, Kang R, El-Husseini Ael-D, Bredt DS (2003) Lipid- and protein-mediated multimerization of PSD95: implications for receptor clustering and assembly of synaptic protein networks. J Cell Sci 116:3213-3219.

Codazzi F, Di Cesare A, Chiulli N, Albanese A, Meyer T, Zacchetti D, Grohovaz F (2006) Synergistic control of protein kinase $\mathrm{C} \gamma$ activity by ionotropic and metabotropic glutamate receptor inputs in hippocampal neurons. J Neurosci 26:3404-3411.

Collingridge GL, Isaac JT, Wang YT (2004) Receptor trafficking and synaptic plasticity. Nat Rev Neurosci 5:952-962.

Cook WJ, Walter LJ, Walter MR (1994) Drug binding by calmodulin: crystal structure of a calmodulin-trifluoperazine complex. Biochemistry 33:1525915265.

Corvol JC, Valjent E, Toutant M, Enslen H, Irinopoulou T, Lev S, Hervé D, Girault JA (2005) Depolarization activates ERK and proline-rich tyrosine kinase 2 (PYK2) independently in different cellular compartments in hippocampal slices. J Biol Chem 280:660-668.

Craven SE, El-Husseini AE, Bredt DS (1999) Synaptic targeting of the postsynaptic density protein PSD-95 mediated by lipid and protein motifs. Neuron 22:497-509.

Crossthwaite AJ, Valli H, Williams RJ (2004) Inhibiting Src family tyrosine kinase activity blocks glutamate signalling to ERK1/2 and Akt/PKB but not JNK in cultured striatal neurones. J Neurochem 88:1127-1139.

Davare MA, Hell JW (2003) Increased phosphorylation of the neuronal L-type $\mathrm{Ca}^{2+}$ channel $\mathrm{Ca}_{\mathrm{v}} 1.2$ during aging. Proc Natl Acad Sci U S A 100:16018-16023.

De Camilli P, Harris SM Jr, Huttner WB, Greengard P (1983) Synapsin I (Protein I), a nerve terminal-specific phosphoprotein. II. Its specific association with synaptic vesicles demonstrated by immunocytochemistry in agarose-embedded synaptosomes. J Cell Biol 96:1355-1373.

Della Rocca GJ, van Biesen T, Daaka Y, Luttrell DK, Luttrell LM, Lefkowitz RJ (1997) Ras-dependent mitogen-activated protein kinase activation by G protein-coupled receptors. Convergence of Gi- and Gq-mediated pathways on calcium/calmodulin, Pyk2, and Src kinase. J Biol Chem 272:19125-19132.

Dikic I, Tokiwa G, Lev S, Courtneidge SA, Schlessinger J (1996) A role for Pyk2 and Src in linking G-protein-coupled receptors with MAP kinase activation. Nature 383:547-550.

Dunty JM, Schaller MD (2002) The N termini of focal adhesion kinase family members regulate substrate phosphorylation, localization, and cell morphology. J Biol Chem 277:45644-45654.

Earp HS, Huckle WR, Dawson TL, Li X, Graves LM, Dy R (1995) Angiotensin II activates at least two tyrosine kinases in rat liver epithelial cells. J Biol Chem 270:28440-28447.

El-Husseini Ael-D, Schnell E, Dakoji S, Sweeney N, Zhou Q, Prange O, Gauthier-Campbell C, Aguilera-Moreno A, Nicoll RA, Bredt DS (2002)
Synaptic strength regulated by palmitate cycling on PSD-95. Cell 108:849-863.

Fong DK, Rao A, Crump FT, Craig AM (2002) Rapid synaptic remodeling by protein kinase C: reciprocal translocation of NMDA receptors and calcium/calmodulin-dependent kinase II. J Neurosci 22:2153-2164.

Frank GD, Saito S, Motley ED, Sasaki T, Ohba M, Kuroki T, Inagami T, Eguchi S (2002) Requirement of $\mathrm{Ca}^{2+}$ and PKCdelta for Janus kinase 2 activation by angiotensin II: involvement of PYK2. Mol Endocrinol 16:367-377.

Friedman HV, Bresler T, Garner CC, Ziv NE (2000) Assembly of new individual excitatory synapses: time course and temporal order of synaptic molecule recruitment. Neuron 27:57-69.

Fukunaga Y, Matsubara M, Nagai R, Miyazawa A (2005) The interaction between PSD-95 and $\mathrm{Ca}^{2+} /$ calmodulin is enhanced by PDZ-binding proteins. J Biochem 138:177-182.

Gardoni F, Bellone C, Viviani B, Marinovich M, Meli E, PellegriniGiampietro DE, Cattabeni F, Di Luca M (2002) Lack of PSD-95 drives hippocampal neuronal cell death through activation of an alpha CaMKII transduction pathway. Eur J Neurosci 16:777-786.

Girault JA, Costa A, Derkinderen P, Studler JM, Toutant M (1999) FAK and PYK2/CAKbeta in the nervous system: a link between neuronal activity, plasticity and survival? Trends Neurosci 22:257-263.

Goedert M, Crowther RA, Garner CC (1991) Molecular characterization of microtubule-associated proteins tau and MAP2. Trends Neurosci 14:193-199.

Guo J, Meng F, Fu X, Song B, Yan X, Zhang G (2004) N-methyl-D-aspartate receptor and L-type voltage-gated $\mathrm{Ca}^{2+}$ channel activation mediate proline-rich tyrosine kinase 2 phosphorylation during cerebral ischemia in rats. Neurosci Lett 355:177-180.

Haglund K, Ivankovic-Dikic I, Shimokawa N, Kruh GD, Dikic I (2004) Recruitment of Pyk2 and $\mathrm{Cbl}$ to lipid rafts mediates signals important for actin reorganization in growing neurites. J Cell Sci 117:2557-2568.

Haunsø A, Simpson J, Antoni FA (2003) Small ligands modulating the activity of mammalian adenylyl cyclases: a novel mode of inhibition by calmidazolium. Mol Pharmacol 63:624-631.

Heidinger V, Manzerra P, Wang XQ, Strasser U, Yu SP, Choi DW, Behrens MM (2002) Metabotropic glutamate receptor 1-induced upregulation of NMDA receptor current: mediation through the Pyk2/Src-family kinase pathway in cortical neurons. J Neurosci 22:5452-5461.

Hell JW, Westenbroek RE, Warner C, Ahlijanian MK, Prystay W, Gilbert MM, Snutch TP, Catterall WA (1993) Identification and differential subcellular localization of the neuronal class C and class D L-type calcium channel a1 subunits. J Cell Biol 123:949-962.

Hell JW, Yokoyama CT, Breeze LJ, Chavkin C, Catterall WA (1995) Phosphorylation of presynaptic and postsynaptic calcium channels by cAMP-dependent protein kinase in hippocampal neurons. EMBO J 14:3036-3044.

Hell JW, Westenbroek RE, Breeze LJ, Wang KK, Chavkin C, Catterall WA (1996) $N$-methyl-D-aspartate receptor-induced proteolytic conversion of postsynaptic class C L-type calcium channels in hippocampal neurons. Proc Natl Acad Sci U S A 93:3362-3367.

Hirokawa N, Hisanaga S, Shiomura Y (1988) MAP2 is a component of crossbridges between microtubules and neurofilaments in the neuronal cytoskeleton: quick-freeze, deep-etch immunoelectron microscopy and reconstitution studies. J Neurosci 8:2769-2779.

Hou XY, Zhang GY, Wang DG, Guan QH, Yan JZ (2005) Suppression of postsynaptic density protein 95 by antisense oligonucleotides diminishes postischemic pyramidal cell death in rat hippocampal CA1 subfield. Neurosci Lett 385:230-233.

Huang Y, Lu W, Ali DW, Pelkey KA, Pitcher GM, Lu YM, Aoto H, Roder JC, Sasaki T, Salter MW, MacDonald JF (2001) CAKbeta/Pyk2 kinase is a signaling link for induction of long-term potentiation in CA1 hippocampus. Neuron 29:485-496.

Hubbard SR, Miller WT (2007) Receptor tyrosine kinases: mechanisms of activation and signaling. Curr Opin Cell Biol 19:117-123.

Hunt CA, Schenker LJ, Kennedy MB (1996) PSD-95 is associated with the postsynaptic density and not with the presynaptic membrane at forebrain synapses. J Neurosci 16:1380-1388.

Ivankovic-Dikic I, Grönroos E, Blaukat A, Barth BU, Dikic I (2000) Pyk2 and FAK regulate neurite outgrowth induced by growth factors and integrins. Nat Cell Biol 2:574-581.

Johnston JC, Gasmi M, Lim LE, Elder JH, Yee JK, Jolly DJ, Campbell KP, 
Davidson BL, Sauter SL (1999) Minimum requirements for efficient transduction of dividing and nondividing cells by feline immunodeficiency virus vectors. J Virol 73:4991-5000.

Kim E, Sheng M (2004) PDZ domain proteins of synapses. Nat Rev Neurosci 5:771-781.

Kim E, Cho KO, Rothschild A, Sheng M (1996) Heteromultimerization and NMDA receptor-clustering activity of chapsyn-110, a member of the PSD-95 family of proteins. Neuron 17:103-113.

Kohno T, Matsuda E, Sasaki H, Sasaki T (2008) Protein-tyrosine kinase CAKbeta/PYK2 is activated by binding $\mathrm{Ca}^{2+} /$ calmodulin to FERM F2 alpha2 helix and thus forming its dimer. Biochem J 410:513-523.

Köhr G, Seeburg PH (1996) Subtype-specific regulation of recombinant NMDA receptor-channels by protein tyrosine kinases of the src family. J Physiol 492:445-452.

Kornau HC, Schenker LT, Kennedy MB, Seeburg PH (1995) Domain interaction between NMDA receptor subunits and the postsynaptic density protein PSD-95. Science 269:1737-1740.

Kwon HB, Castillo PE (2008) Long-term potentiation selectively expressed by NMDA receptors at hippocampal mossy fiber synapses. Neuron 57:108-120.

Lee JM, Zipfel GJ, Choi DW (1999) The changing landscape of ischaemic brain injury mechanisms. Nature [Suppl] 399:A7-A14.

Leonard AS, Davare MA, Horne MC, Garner CC, Hell JW (1998) SAP97 is associated with the a-amino-3-hydroxy-5-methylisoxazole-4-propionic acid receptor GluR1 subunit. J Biol Chem 273:19518-19524.

Leonard AS, Lim IA, Hemsworth DE, Horne MC, Hell JW (1999) Calcium/ calmodulin-dependent protein kinase II is associated with the N-methylD-aspartate receptor. Proc Natl Acad Sci U S A 96:3239-3244.

Leonard AS, Bayer KU, Merrill MA, Lim IA, Shea MA, Schulman H, Hell JW (2002) Regulation of calcium/calmodulin-dependent protein kinase II docking to $\mathrm{N}$-methyl-D-aspartate receptors by calcium/calmodulin and a-actinin. J Biol Chem 277:48441-48448.

Lev S, Moreno H, Martinez R, Canoll P, Peles E, Musacchio JM, Plowman GD, Rudy B, Schlessinger J (1995) Protein tyrosine kinase PYK2 involved in $\mathrm{Ca}^{2+}$-induced regulation of ion channel and MAP kinase functions. Nature 376:737-745.

Li X, Dy RC, Cance WG, Graves LM, Earp HS (1999) Interactions between two cytoskeleton-associated tyrosine kinases: calcium-dependent tyrosine kinase and focal adhesion tyrosine kinase. J Biol Chem 274:8917-8924.

Lietha D, Cai X, Ceccarelli DF, Li Y, Schaller MD, Eck MJ (2007) Structural basis for the autoinhibition of focal adhesion kinase. Cell 129:1177-1187.

Lim IA, Hall DD, Hell JW (2002) Selectivity and promiscuity of the first and second PDZ domains of PSD-95 and synapse-associated protein 102. J Biol Chem 277:21697-21711.

Lim IA, Merrill MA, Chen Y, Hell JW (2003) Disruption of the NMDA receptor-PSD-95 interaction in hippocampal neurons with no obvious physiological short-term effect. Neuropharmacology 45:738-754.

Liu J, Fukunaga K, Yamamoto H, Nishi K, Miyamoto E (1999) Differential roles of $\mathrm{Ca}^{2+} /$ calmodulin-dependent protein kinase II and mitogenactivated protein kinase activation in hippocampal long-term potentiation. J Neurosci 19:8292-8299.

Liu Y, Zhang G, Gao C, Hou X (2001) NMDA receptor activation results in tyrosine phosphorylation of NMDA receptor subunit 2A(NR2A) and interaction of Pyk2 and Src with NR2A after transient cerebral ischemia and reperfusion. Brain Res 909:51-58.

Lu WY, Xiong ZG, Lei S, Orser BA, Dudek E, Browning MD, MacDonald JF (1999) G-protein-coupled receptors act via protein kinase C and Src to regulate NMDA receptors. Nat Neurosci 2:331-338.

Lu WY, Jackson MF, Bai D, Orser BA, MacDonald JF (2000) In CA1 pyramidal neurons of the hippocampus protein kinase $\mathrm{C}$ regulates calciumdependent inactivation of NMDA receptors. J Neurosci 20:4452-4461.

Lu Y, Allen M, Halt AR, Weisenhaus M, Dallapiazza RF, Hall DD, Usachev YM, McKnight GS, Hell JW (2007) Age-dependent requirement of AKAP150-anchored PKA and GluR2-lacking AMPA receptors in LTP. EMBO J 26:4879-4890.

Lu YM, Roder JC, Davidow J, Salter MW (1998) Src activation in the induction of long-term potentiation in CA1 hippocampal neurons. Science 279:1363-1367.

Malenka RC, Bear MF (2004) LTP and LTD: an embarrassment of riches. Neuron 44:5-21.
Martin SJ, Grimwood PD, Morris RG (2000) Synaptic plasticity and memory: an evaluation of the hypothesis. Annu Rev Neurosci 23:649-711.

Masuko N, Makino K, Kuwahara H, Fukunaga K, Sudo T, Araki N, Yamamoto H, Yamada Y, Miyamoto E, Saya H (1999) Interaction of NE-dlg/SAP102, a neuronal and endocrine tissue-specific membraneassociated guanylate kinase protein, with calmodulin and PSD-95/SAP90. A possible regulatory role in molecular clustering at synaptic sites. J Biol Chem 274:5782-5790.

McGee AW, Bredt DS (1999) Identification of an intramolecular interaction between the $\mathrm{SH} 3$ and guanylate kinase domains of PSD-95. J Biol Chem 274:17431-17436.

McGee AW, Dakoji SR, Olsen O, Bredt DS, Lim WA, Prehoda KE (2001) Structure of the SH3-guanylate kinase module from PSD-95 suggests a mechanism for regulated assembly of MAGUK scaffolding proteins. Mol Cell 8:1291-1301.

Merrill MA, Chen Y, Strack S, Hell JW (2005) Activity-driven postsynaptic translocation of CaMKII. Trends Pharmacol Sci 26:645-653.

Merrill MA, Malik Z, Akyol Z, Bartos JA, Leonard AS, Hudmon A, Shea MA, Hell JW (2007) Displacement of alpha-actinin from the NMDA receptor NR1 C0 domain by $\mathrm{Ca}^{2+} /$ calmodulin promotes CaMKII binding. Biochemistry 46:8485-8497.

Paarmann I, Spangenberg O, Lavie A, Konrad M (2002) Formation of complexes between $\mathrm{Ca}^{2+}$ calmodulin and the synapse-associated protein SAP97 requires the $\mathrm{SH} 3$ domain-guanylate kinase domain-connecting HOOK region. J Biol Chem 277:40832-40838.

Park SY, Avraham H, Avraham S (2000) Characterization of the tyrosine kinases RAFTK/Pyk2 and FAK in nerve growth factor-induced neuronal differentiation. J Biol Chem 275:19768-19777.

Park SY, Avraham HK, Avraham S (2004) RAFTK/Pyk2 activation is mediated by trans-acting autophosphorylation in a Src-independent manner. J Biol Chem 279:33315-33322.

Pastalkova E, Serrano P, Pinkhasova D, Wallace E, Fenton AA, Sacktor TC (2006) Storage of spatial information by the maintenance mechanism of LTP. Science 313:1141-1144.

Pawson T, Scott JD (1997) Signaling through scaffold, anchoring, and adaptor proteins. Science 278:2075-2080.

Pittman RN, Wang S, DiBenedetto AJ, Mills JC (1993) A system for characterizing cellular and molecular events in programmed neuronal cell death. J Neurosci 13:3669-3680.

Rao A, Kim E, Sheng M, Craig AM (1998) Heterogeneity in the molecular composition of excitatory postsynaptic sites during development of hippocampal neurons in culture. J Neurosci 18:1217-1229.

Rebecchi MJ, Pentyala SN (2000) Structure, function, and control of phosphoinositide-specific phospholipase C. Physiol Rev 80:1291-1335.

Rebola N, Lujan R, Cunha RA, Mulle C (2008) Adenosine A2A receptors are essential for long-term potentiation of NMDA-EPSCs at hippocampal mossy fiber synapses. Neuron 57:121-134.

Rothman SM, Olney JW (1987) Excitotoxicity and the NMDA receptor. Trends Neurosci 10:299-302.

Sabri A, Govindarajan G, Griffin TM, Byron KL, Samarel AM, Lucchesi PA (1998) Calcium- and protein kinase C-dependent activation of the tyrosine kinase PYK2 by angiotensin II in vascular smooth muscle. Circ Res 83:841-851.

Sakata A, Ida E, Tominaga M, Onoue K (1987) Calmodulin inhibitors, W-7 and TFP, block the calmodulin-independent activation of NADPHoxidase by arachidonate in a cell-free system. Biochem Biophys Res Commun 148:112-119.

Salter MW, Kalia LV (2004) Src kinases: a hub for NMDA receptor regulation. Nat Rev Neurosci 5:317-328.

Sans N, Petralia RS, Wang YX, Blahos J 2nd, Hell JW, Wenthold RJ (2000) A developmental change in NMDA receptor-associated proteins at hippocampal synapses. J Neurosci 20:1260-1271.

Sans N, Wang PY, Du Q, Petralia RS, Wang YX, Nakka S, Blumer JB, Macara IG, Wenthold RJ (2005) mPins modulates PSD-95 and SAP102 trafficking and influences NMDA receptor surface expression. Nat Cell Biol 7:1179-1190.

Sasaki H, Nagura K, Ishino M, Tobioka H, Kotani K, Sasaki T (1995) Cloning and characterization of cell adhesion kinase beta, a novel proteintyrosine kinase of the focal adhesion kinase subfamily. J Biol Chem 270:21206-21219.

Schaller MD (2008) Calcium-dependent Pyk2 activation: a role for calmodulin? Biochem J 410:e3-e4. 
Schlüter OM, Xu W, Malenka RC (2006) Alternative N-terminal domains of PSD-95 and SAP97 govern activity-dependent regulation of synaptic AMPA receptor function. Neuron 51:99-111.

Schweitzer E (1987) Coordinated release of ATP and ACh from cholinergic synaptosomes and its inhibition by calmodulin antagonists. J Neurosci 7:2948-2956.

Seabold GK, Burette A, Lim IA, Weinberg RJ, Hell JW (2003) Interaction of the tyrosine kinase Pyk2 with the $N$-methyl-D-aspartate receptor complex via the src homology 3 domains of PSD-95 and SAP102. J Biol Chem 278:15040-15048.

Shapira M, Zhai RG, Dresbach T, Bresler T, Torres VI, Gundelfinger ED, Ziv NE, Garner CC (2003) Unitary assembly of presynaptic active zones from Piccolo-Bassoon transport vesicles. Neuron 38:237-252.

Shen K, Meyer T (1999) Dynamic control of CaMKII Translocation in hippocampal neurons by NMDA receptor stimulation. Science 284:162-166.

Shin H, Hsueh YP, Yang FC, Kim E, Sheng M (2000) An intramolecular interaction between Src homology 3 domain and guanylate kinase-like domain required for channel clustering by postsynaptic density-95/ SAP90. J Neurosci 20:3580-3587.

Siciliano JC, Toutant M, Derkinderen P, Sasaki T, Girault JA (1996) Differential regulation of proline-rich tyrosine kinase $2 /$ cell adhesion kinase beta (PYK2/CAKbeta) and pp125(FAK) by glutamate and depolarization in rat hippocampus. J Biol Chem 271:28942-28946.

Sorokin A, Kozlowski P, Graves L, Philip A (2001) Protein-tyrosine kinase Pyk2 mediates endothelin-induced p38 MAPK activation in glomerular mesangial cells. J Biol Chem 276:21521-21528.

Stein CS, Davidson BL (2002) Gene transfer to the brain using feline immunodeficiency virus-based lentivirus vectors. Methods Enzymol 346:433454.

Sun XX, Hodge JJ, Zhou Y, Nguyen M, Griffith LC (2004) The eag potassium channel binds and locally activates calcium/calmodulin-dependent protein kinase II. J Biol Chem 279:10206-10214.

Tomita S, Nicoll RA, Bredt DS (2001) PDZ protein interactions regulating glutamate receptor function and plasticity. J Cell Biol 153:F19-F24.

Ullrich A, Schlessinger J (1990) Signal transduction by receptors with tyrosine kinase activity. Cell 61:203-212.

Valtschanoff JG, Weinberg RJ (2001) Laminar organization of the NMDA receptor complex within the postsynaptic density. J Neurosci 21:1211-1217.

Vandonselaar M, Hickie RA, Quail JW, Delbaere LT (1994) Trifluoperazine- induced conformational change in $\mathrm{Ca}^{2+}$-calmodulin. Nat Struct Biol 1:795-801.

Wakamori M, Hidaka H, Akaike N (1993) Hyperpolarizing muscarinic responses of freshly dissociated rat hippocampal CA1 neurones. J Physiol 463:585-604.

Wang LY, MacDonald JF (1995) Modulation by magnesium of the affinity of NMDA receptors for glycine in murine hippocampal neurones. J Physiol 486:83-95.

Wang YT, Salter MW (1994) Regulation of NMDA receptors by tyrosine kinases and phosphatases. Nature 369:233-235.

Whitlock JR, Heynen AJ, Shuler MG, Bear MF (2006) Learning induces long-term potentiation in the hippocampus. Science 313:1093-1097.

Wong W, Scott JD (2004) AKAP signalling complexes: focal points in space and time. Nat Rev Mol Cell Biol 5:959-970.

Wu SS, Jácamo RO, Vong SK, Rozengurt E (2006) Differential regulation of Pyk2 phosphorylation at Tyr-402 and Tyr-580 in intestinal epithelial cells: roles of calcium, Src, Rho kinase, and the cytoskeleton. Cell Signal 18:1932-1940.

Xiong ZG, Pelkey KA, Lu WY, Lu YM, Roder JC, MacDonald JF, Salter MW (1999) Src potentiation of NMDA receptors in hippocampal and spinal neurons is not mediated by reducing zinc inhibition. J Neurosci 19:RC37(1-6).

Xu J, Weerapura M, Ali MK, Jackson MF, Li H, Lei G, Xue S, Kwan CL, Manolson MF, Yang K, Macdonald JF, Yu XM (2008) Control of excitatory synaptic transmission by C-terminal Src kinase. J Biol Chem 283:17503-17514.

Yu H, Li X, Marchetto GS, Dy R, Hunter D, Calvo B, Dawson TL, Wilm M, Anderegg RJ, Graves LM, Earp HS (1996) Activation of a novel calciumdependent protein-tyrosine kinase. Correlation with c-Jun N-terminal kinase but not mitogen-activated protein kinase activation. J Biol Chem 271:29993-29998.

Yu XM, Askalan R, Keil GJ 2nd, Salter MW (1997) NMDA channel regulation by channel-associated protein tyrosine kinase Src. Science 275:674-678.

Zhai RG, Vardinon-Friedman H, Cases-Langhoff C, Becker B, Gundelfinger ED, Ziv NE, Garner CC (2001) Assembling the presynaptic active zone: a characterization of an active one precursor vesicle. Neuron 29:131-143.

Zhang X, Gureasko J, Shen K, Cole PA, Kuriyan J (2006) An allosteric mechanism for activation of the kinase domain of epidermal growth factor receptor. Cell 125:1137-1149. 